\title{
Pharmacological Targeting of the Transcription Factor Nrf2 at the Basal Ganglia Provides Disease Modifying Therapy for Experimental Parkinsonism
}

\author{
Agnieszka Jazwa, ${ }^{1, *, \dagger}$ Ana I. Rojo, ${ }^{1,2, *}$ Nadia G. Innamorato, ${ }^{1,3,4}$ Marlen Hesse, ${ }^{1,3,4}$ \\ Javier Fernández-Ruiz, ${ }^{1,2,5}$ and Antonio Cuadrado ${ }^{1,3,4}$
}

\begin{abstract}
Current therapies for motor symptoms of Parkinson's disease (PD) are based on dopamine replacement. However, the disease progression remains unaffected, because of continuous dopaminergic neuron loss. Since oxidative stress is actively involved in neuronal death in PD, pharmacological targeting of the antioxidant machinery may have therapeutic value. Here, we analyzed the relevance of the antioxidant phase II response mediated by the transcription factor NF-E2-related factor 2 (Nrf2) on brain protection against the parkinsonian toxin methyl-4-phenyl-1,2,3,6tetrahydropyridine (MPTP). Intraperitoneal administration of the potent $\mathrm{Nrf} 2$ activator sulforaphane (SFN) increased Nrf2 protein levels in the basal ganglia and led to upregulation of phase II antioxidant enzymes heme oxygenase-1 (HO-1) and $\mathrm{NAD}(\mathrm{P}) \mathrm{H}$ quinone oxidoreductase (NQO1). In wild-type mice, but not in Nrf2-knockout mice, SFN protected against MPTP-induced death of nigral dopaminergic neurons. The neuroprotective effects were accompanied by a decrease in astrogliosis, microgliosis, and release of pro-inflammatory cytokines. These results provide strong pharmacokinetic and biochemical evidence for activation of Nrf2 and phase II genes in the brain and also offer a neuroprotective strategy that may have clinical relevance for PD therapy. Antioxid. Redox Signal. 14, 2347-2360.
\end{abstract}

\section{Introduction}

$\mathbf{O}$ XIDATIVE STRESS derived from oxidative dopamine (DA) metabolism, mitochondrial dysfunction, or inflammation plays a critical role in the pathogenesis of both familiar and sporadic forms of Parkinson's disease (PD) $(2,14)$. Based on this fact, we have determined in this study whether the transcription factor NF-E2-related factor-2 (Nrf2), master regulator of redox homeostasis, might be a therapeutic target to slow PD progression.

Nrf2 regulates the expression of a battery of genes involved in defense against oxidant and xenobiotic compounds that constitute the so-called phase II response (2). These genes code heme oxygenase-1 (HO-1), NAD(P)H quinone oxidoreductase 1 (NQO1), glutathione reductase, and the catalytic and modulator subunits of $\gamma$-glutamyl cysteine ligase (GCL-C and
GCL-M, respectively) among many others $(13,15-17)$. In Supplementary Figure S1 (Supplementary Data are available online at www.liebertonline.com/ars), we suggest a role for some Nrf2-regulated genes in elimination of hydrogen peroxide and DA-quinones in dopaminergic neurons.

Several important findings connect Nrf2 with PD. Nrf2 activity declines with age, which is the main risk factor for PD. Interestingly, the transcriptional activity of Nrf2 can be restored pharmacologically in old animals (30). In nigral dopaminergic neurons, Nrf2 is located at the cytosol, whereas in age-matched patients with PD, Nrf2 is found at the nucleus, suggesting an attempt to reduce oxidative stress through Nrf2-dependent transcription of antioxidant enzymes (22). Finally, a functional haplotype in the Nrf2 gene promoter, which confers high transcriptional activity (20), has been reported to be protective in two groups of European patients

\footnotetext{
${ }^{1}$ Centro de Investigación Biomédica en Red sobre Enfermedades Neurodegenerativas (CIBERNED), Madrid, Spain.

${ }^{2}$ Departamento de Bioquímica y Biología Molecular, Facultad de Medicina, Universidad Complutense de Madrid (UCM), Madrid, Spain.

${ }^{3}$ Departamento de Bioquímica e Instituto de Investigaciones Biomédicas "Alberto Sols" Consejo Superior de Investigaciones Científicas (CSIC) and Universidad Autónoma de Madrid (UAM), Madrid, Spain.

${ }^{4}$ Instituto de Investigación Sanitaria La Paz (IdiPaz), Madrid, Spain.

${ }^{5}$ Instituto Ramón y Cajal de Investigación Sanitaria (IRYCIS), Madrid, Spain.

*These two authors should be considered as first authors.

$\dagger$ Current affiliation: Department of Medical Biotechnology, Faculty of Biochemistry, Biophysics and Biotechnology, Jagiellonian University, Krakow, Poland.
} 
with PD (32). Concerning animal models, Nrf2-deficient mice are more susceptible to 1-methyl-4-phenyl-1,2,3,6tetrahydropyridine (MPTP)-induced neurodegeneration and inflammation $(1,4,24)$.

In the absence of stimuli, Nrf2 is located at the cytosol, bound to a protein, Keap1, that targets it for degradation through the ubiquitin-proteasome pathway and, therefore, it has a very short half-life. Several drugs alter the Nrf2/Keap1 complex through adduct formation with specific Keap1 cysteines, leading to Nrf2 stabilization and translocation to the nucleus where it activates phase II gene transcription (16). In the present study, we chose sulforaphane (SFN) to target Nrf2 in the basal ganglia. SFN is an isothiocyanate found in cruciferous vegetables such as broccoli that has gained attention as a chemopreventative (34) and anti-inflammatory compound (11) mostly in in vitro experiments or in peripheral tissues.

Our results indicate that indeed SFN crosses the blood brain barrier, induces an Nrf2-dependent phase II response in the basal ganglia, and protects against nigral dopaminergic cell death, astrogliosis, and microgliosis in the MPTP mouse model of PD.

\section{Materials and Methods}

\section{Animals and treatments}

All animal protocols were approved by the Ethical Committee for Research of the Universidad Autónoma de Madrid following institutional, Spanish, and European guidelines (Boletin Oficial del Estado of 18 March 1988; and 86/609/EEC, 2003/65/EC European Council Directives). Nrf2-knockout mice and their wild-type littermates were obtained thanks to the courtesy of Dr. Masayuki Yamamoto (Tohoku University Graduate School of Medicine, Sendai, Japan) (12). MPTP (Sigma-Aldrich, St. Louis, MO) and SFN (LKT Laboratories, St. Paul, MN) were prepared in saline solution just before use. Animals were anesthetized with $8 \mathrm{mg} / \mathrm{kg}$ ketamine and $1.2 \mathrm{mg} / \mathrm{kg}$ xylazine, and some of them were perfused with $4 \%$ paraformaldehyde. The nonperfused brains were dissected, and two regions corresponding to striatum (STR) and ventral midbrain $(\mathrm{VMB})$ were rapidly frozen at $-80^{\circ} \mathrm{C}$ for RNA, protein, and/or DA measurements.

\section{Analysis of $m R N A$ levels by quantitative polymerase chain reaction}

Total RNA was extracted from STR using TRIzol reagent according to the manufacturer's instructions (Invitrogen, Paisley, United Kingdom). One micrograms of RNA from the different treatments was reverse-transcribed in $20 \mu \mathrm{L}$ using High Capacity RNA-to-cDNA Kit (Applied Biosystems, Carlsbad, CA) according to manufacturer's instructions. Polymerase chain reactions (PCRs) and primers have been previously described (11). All PCRs were performed in triplicate.

\section{Determination of DA, DOPAC, SFN, and MPP ${ }^{+}$ by high-performance liquid chromatography}

For high-performance liquid chromatography (HPLC) analysis of DA and its major intraneuronal degradation product, dihydroxyphenylacetic acid (DOPAC), STRs were homogenized in 50 volumes of ice-cold $0.2 \mathrm{~N}$ perchloric acid containing $0.2 \mathrm{mM}$ sodium disulfide and $0.45 \mathrm{mM}$ EDTA. Dihydroxybenzylamine was added as an internal standard.
HPLCs were performed as previously described (9). For HPLC determination of SFN, STR and VMB were dissected and rapidly frozen at $-80^{\circ} \mathrm{C}$. Samples were sonicated in 10 volumes $(\mathrm{w} / \mathrm{v})$ of methanol and analyzed as previously described (11). For determination of 1-methyl-4-phenylpyridinium $\left(\mathrm{MPP}^{+}\right)$levels, STR and VMB were dissected and rapidly frozen at $-80^{\circ} \mathrm{C}$. Samples were sonicated in $10 \mathrm{vol}-$ umes (w/v) of $5 \%$ trichloroacetic acid containing $10 \mu \mathrm{g} / \mathrm{mL}$ of 4-phenylpyridine (Sigma-Aldrich) as internal standard and analyzed as previously described $(23,25)$.

\section{Immunohistochemistry}

Animals were perfused, brains fixed, and $30-\mu$ m-thick coronal sections obtained as previously described (24). Sections were rinsed in $100 \mathrm{mM}$ Tris- $\mathrm{HCl}, \mathrm{pH} 7.6$, and $225 \mathrm{mM} \mathrm{NaCl}$ (TBS). Tissue peroxidase was inactivated by incubating in $10 \%$ methanol and 3\% hydrogen peroxide in Tris-buffered saline (TBS) for $30 \mathrm{~min}$. After three washes in TBS, sections were incubated for $3 \mathrm{~h}$ in blocking solution ( $10 \%$ goat serum, $0.3 \%$ Triton $\mathrm{X}-100$ in TBS) and then for $24 \mathrm{~h}$ at $4^{\circ} \mathrm{C}$ with mouse anti-tyrosine hydroxylase (TH) (1:500; Millipore, Billerica, MA), rabbit antiglial fibrillary acidic protein (GFAP) (1:500; Dako, Glostrup, Denkmark), or rabbit anti-Iba1 (1:500; Wako Chemicals, Richmond, VA). Sections were rinsed in TBS, then incubated with rabbit anti-mouse or anti-rabbit secondary antibodies at 1/1000 dilution for $1 \mathrm{~h}$ at room temperature (Vector Labs, Burlingame, CA). Sections were subsequently developed by avidin-biotin peroxidase complex system following manufacturer's instructions (ABC Kit, Vector Labs). Control sections were treated with the same protocol but omitting the primary antibody.

\section{Immunofluorescence}

Parallel series of $30-\mu$ m-thick coronal sections were rinsed in phosphate-buffered saline (PBS) and incubated for $1 \mathrm{~h}$ in blocking solution. Double immunofluorescence was performed by incubating the sections for $24 \mathrm{~h}$ at $4^{\circ} \mathrm{C}$ with the following primary antibodies: mouse anti-TH (1:500; Millipore), rabbit anti-GFAP (1:500; Dako), or rabbit anti-Iba1 (1:500; Wako Chemicals), diluted in PBS containing $0.5 \%$ goat serum and $0.3 \%$ Triton $X-100$. Sections were washed thrice in PBS and then incubated with secondary antibodies: Alexa Fluor 488 anti-mouse or Alexa Fluor 546 anti-rabbit (Molecular Probes, Carlsbad, CA) at 1:500 dilution for $1 \mathrm{~h}$. Control sections were treated with the same protocol but omitting the primary antibody. Double immunofluorescence with rabbit antibodies for HO-1 (1:100; Millipore) and either GFAP (1:500; Dako) or Iba1 (1:500; Wako Chemicals) was performed with the use of tyramide amplification system according to the manufacturer's protocol (Perkin Elmer, Boston, MA). Sections were first incubated in 10\% normal goat serum in PBS for $1 \mathrm{~h}$ at room temperature, followed by incubation with the polyclonal rabbit $\mathrm{HO}-1$ antibody in $0.5 \%$ goat serum and $0.2 \%$ Triton X-100 in PBS overnight. Subsequently, the sections were incubated with biotinylated goat anti-rabbit IgG for $1 \mathrm{~h}$, with avidin-biotin complex (ABC; Vector Labs) for $1 \mathrm{~h}$, biotinylated tyramide for $10 \mathrm{~min}$ and then ExtrAvidin-FITC (Sigma-Aldrich) (1:500, $2 \mathrm{~h})$. Second primary antibody was Alexa Fluor 546-conjugated anti-rabbit (Molecular Probes) (1:250, $1 \mathrm{~h}$ ). Control sections were treated with the same protocol but omitting the primary antibody or tyramide amplification step. Fluorescence images were captured in a Leica DMIRE2TCS 
SP2 confocal microscope (Nussloch, Germany). The lasers used were $\mathrm{Ar} 488 \mathrm{~nm}$ for green fluorescence and $\mathrm{Ar} / \mathrm{HeNe}$ $543 \mathrm{~nm}$ for red fluorescence.

\section{Stereological quantification}

Cell counts were performed every four sections (30 $\mu \mathrm{m}$ thick) through the SN using Stereo Investigator Software (MicroBrightfield, Colchester, VT) attached to an E800 Nikon micro- scope (Nikon, Montreal, QC, Canada). SN, excluding ventral tegmental area, was delineated in low magnification $(5 \times$ objective), and a point grid was overlaid onto each section. For Nissl staining, TH-stained sections were rehydrated in xylene and graded alcohols and incubated in Nissl's solution $(0.1 \%$ Cresyl Violet [Sigma-Aldrich], $2.5 \mathrm{~mL}$ acetic acid 10\%) at room temperature for $15 \mathrm{~min}$. Sections were rinsed in deionized water for $5 \mathrm{~min}$, dehydrated in graded alcohols, cleared in xylene, and coverslipped. Stained cells were counted by the optical

FIG. 1. Sulforaphane (SFN) crosses the blood-brain barrier and upregulates NF-E2related factor 2 (Nrf2), and neither SFN treatment nor Nrf2 deficiencies alters 1methyl-4-phenyl-1,2,3,6-tetrahydropyridine (MPTP) conversion. (A, B) High-performance liquid chromatography determination of SFN in striatum (STR) and ventral midbrain (VMB), respectively, after intraperitoneal injection of $50 \mathrm{mg} / \mathrm{kg}$ SFN. (C) Striatal immunoblots showing a time-course induction of Nrf2 by SFN in STR of $\mathrm{Nrf2} 2^{++}$but not $\mathrm{Nrf2}{ }^{-1-}$ mice. Lane $\mathrm{C}$ is a positive control for Nrf2 immunodetection using HEK293T cells transfected with expression vector for mouse Nrf2. Upper panel: Nrf2 protein levels. Lower panel: $\beta$-actin protein levels. (D) densitometric quantification of Nrf2 protein levels from representative immunoblots after normalization by $\beta$-actin in $\mathrm{Nrf} 2^{+/+}$mice. Values represent mean $\pm S D$ of three to five mice per time point. Asterisks denote significant differences between treatments with $p<0.05$. (E) $\mathrm{Nrf} 2^{+/+}$and $\mathrm{Nrf} 2^{-/-}$mice were treated with saline or SFN and sacrificed after $16 \mathrm{~h}$. STR protein extracts were immunoblotted as indicated: Upper panel, anti- dopamine transporter (DAT) antibody; middle panel, anti-monoamine oxidase-B (MAO-B) antibody; lower panel, anti- $\beta$-actin antibody showing similar load of protein per lane. (F) Mice were injected i.p. with saline or SFN, and after $16 \mathrm{~h}$

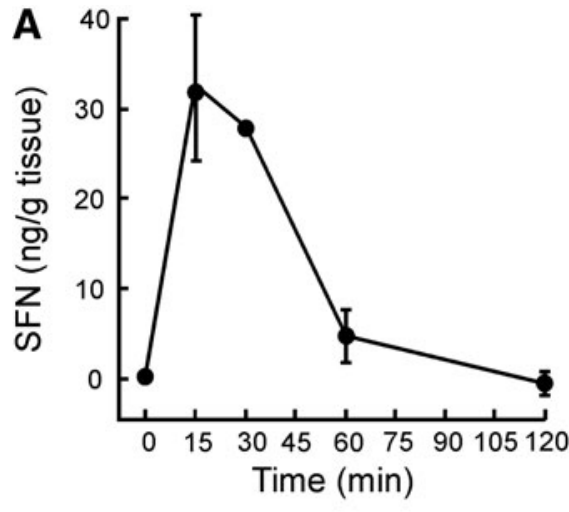

C

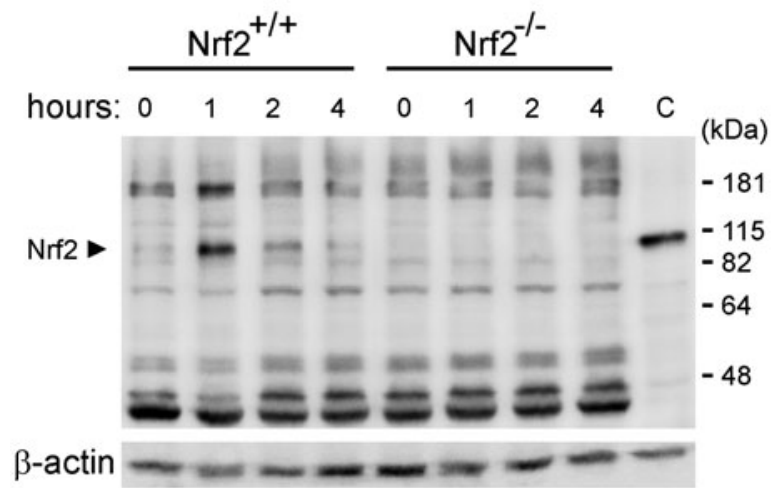

E

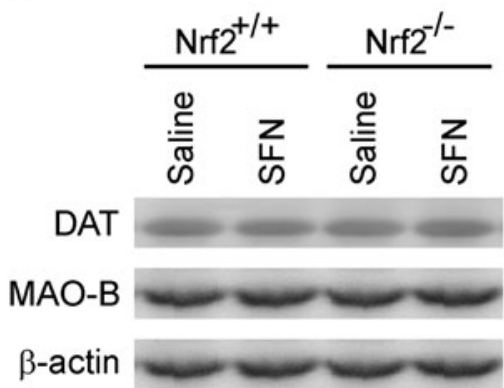

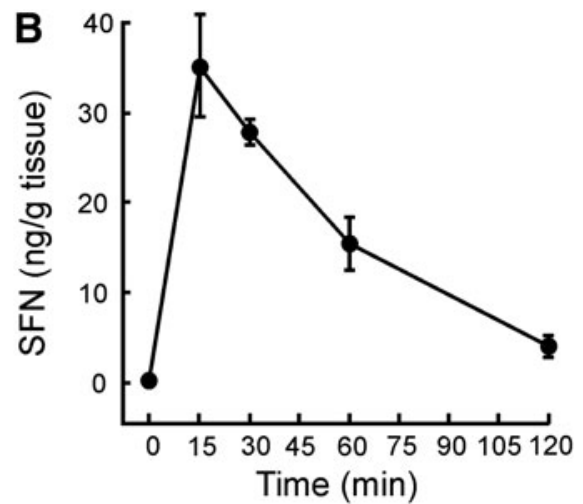

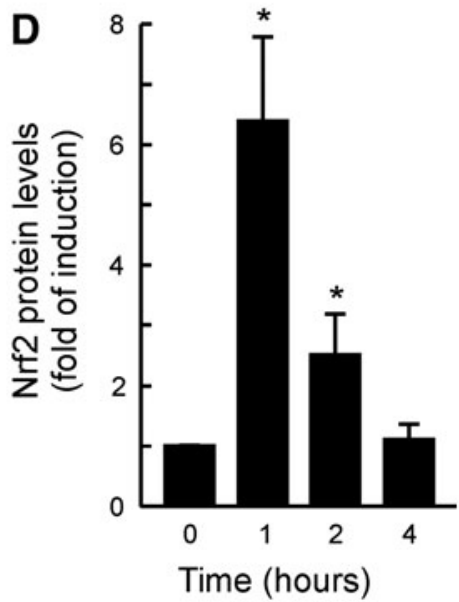

$\mathbf{F}$

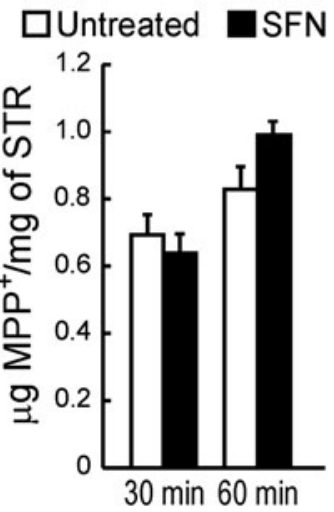

G

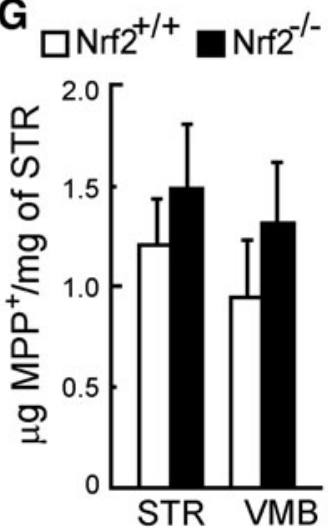

they were injected again with MPTP at a dose of $30 \mathrm{mg} / \mathrm{kg}$. 1-methyl-4-phenylpyridinium $\left(\mathrm{MPP}^{+}\right)$in STR was determined at 30 and $60 \mathrm{~min}$ after MPTP injection. (G) Comparison of $\mathrm{MPP}^{+}$levels in STR and VMB from Nrf2 ${ }^{+/+}$and Nrf2 ${ }^{-/-}$mice $60 \mathrm{~min}$ after injection of MPTP $(30 \mathrm{mg} / \mathrm{kg})$. Values represent mean \pm SD of three to five mice per group and per time point. Differences are not statistically significant. 
fractionator method at high magnification $(63 \times$ objective, N.A. 1.25) distinguishing between TH-positive (TH and Nissl positive) and TH-negative (Nissl positive). TH- and Nissl-stained neurons were counted only when their nuclei were optimally visualized within one focal plane. Nissl-stained neurons were differentiated from non-neuronal cells by clearly defined nucleus, cytoplasm, and a prominent nucleolus. Total numbers of neurons in the SN were calculated as described in (33).

\section{Immunoblotting}

STR and VMB were removed rapidly and homogenized on ice with lysis buffer $(25 \mathrm{mM}$ Tris- $\mathrm{HCl}, \mathrm{pH} 7.6 ; 150 \mathrm{mM} \mathrm{NaCl}$; $1 \mathrm{mM}$ EGTA; $20 \mathrm{mM} \mathrm{NaF} ; 1 \mathrm{mM}$ sodium pyrophosphate; $1 \mathrm{mM} \mathrm{Na} \mathrm{VO}_{4} ; 1 \%$ Nonidet P-40 [Sigma-Aldrich]; $1 \%$ sodium deoxycholate; $0.1 \%$ sodium dodecyl sulfate [SDS]; $1 \mathrm{mM}$ phenyl methyl sulfonyl fluoride, and $1 \mu \mathrm{g} / \mathrm{mL}$ leupeptin). Protein extracts were cleared by centrifugation, and $30 \mu \mathrm{g}$ protein were resolved by SDS-PAGE and transferred to immobilon-P membranes (Millipore). Blots were analyzed with the appropriate antibodies: anti-Nrf2 (1:2000, gift of Dr John D. Hayes, University of Dundee, Dundee, Scotland), a anti-dopamine transporter (DAT) (1:500; Millipore), antimonoamine oxidase-B (MAO-B) (1:500; Santa Cruz Biotechnology), anti-TH (1:2000; Millipore), anti-GFAP (1:2000, Dako), anti-HO-1 (1:2000; Millipore), anti-NQO1 (1:500; Abcam, Cambridge, United Kingdom), anti-GCL-C (gift of Dr Terrance Kavanagh, University of Washington, USA), antiIL-6 (1:1000; Abcam), anti-TNF- $\alpha$ (1:1000; Abcam), and anti$\beta$-actin (1:1000, Santa Cruz Biotechnology). Appropriate peroxidase-conjugated secondary antibodies $(1: 10,000)$ were used to detect the proteins of interest by enhanced chemiluminescence (Advanced ECL; GE Healthcare, Waukesha, WI).

\section{Quantification and statistics}

Density of TH-positive fibers in the STR, HO-1, and GFAP fluorescence and band intensities corresponding to immunoblots were quantified using the MCID software (MCID, Cambridge, United Kingdom). Results are expressed as
A

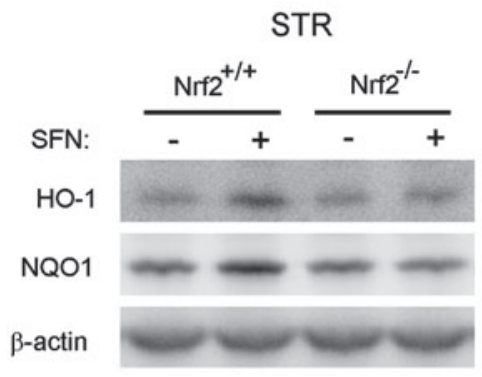

C

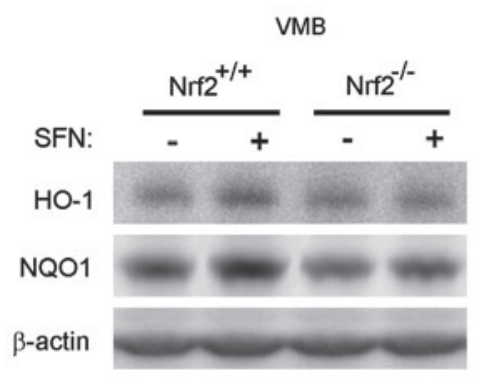

D

B

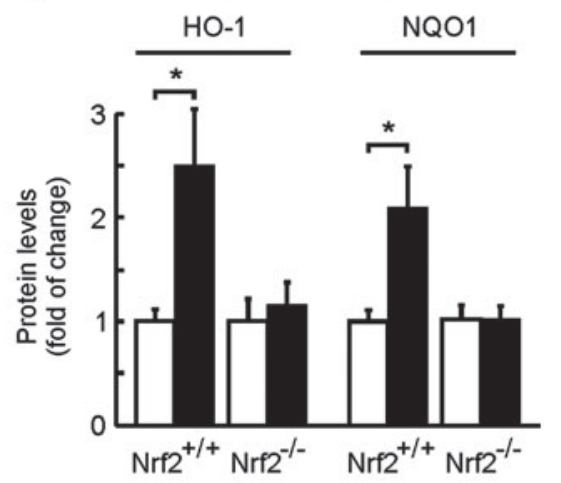

D

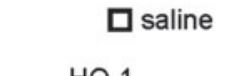

SFN

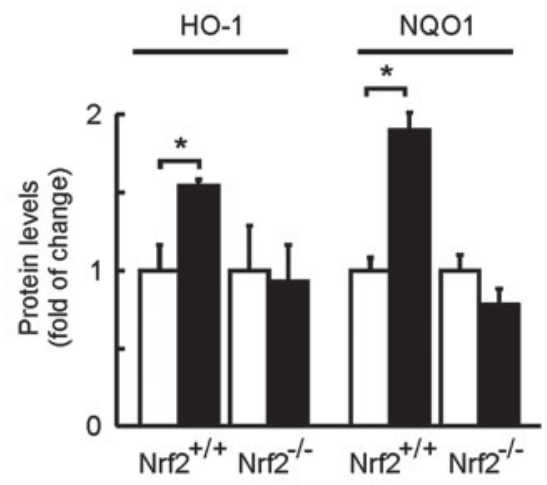

E

E
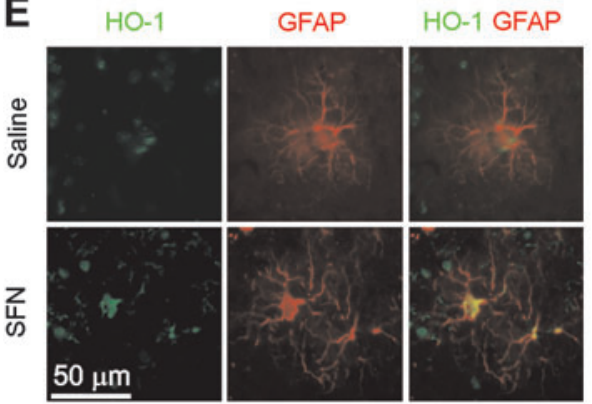

$\mathbf{F}$

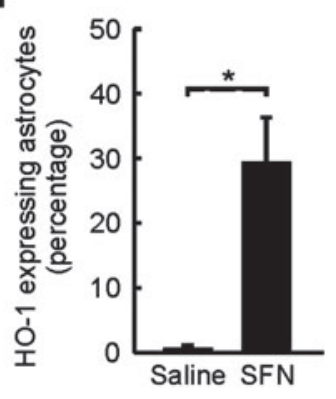

FIG. 2. SFN treatment activates the phase II response in STR and VMB. $\mathrm{Nrf} 2^{+/+}$and $\mathrm{Nrf} 2^{-/-}$mice were treated with SFN and analyzed after $16 \mathrm{~h}$. (A, C) Immunoblots showing induction of heme oxygenase-1 (HO-1) and NAD $(\mathrm{P}) \mathrm{H}$ quinona oxidoreductase 1 (NQO1) in STR and VMB respectively. Upper panels, $\mathrm{HO}-1$ protein levels; middle panels, NQO1 protein levels; lower panels, $\beta$ actin protein levels. (B, D) Densitometric quantifications from representative immunoblots, normalized with $\beta$-actin, of STR and $\mathrm{VMB}$, respectively. Values represent mean \pm $\mathrm{SD}$ of three to five mice per group. Asterisks denote significant differences between treatments with $p<0.05$. (E) Double immunofluorescence of wild-type mice treated with SFN or vehicle according to the protocol depicted in Figure 3A. Sections from day 6 were stained with anti-HO-1 antibody (green) and anti-glial fibrillary acidic protein (GFAP) antibody (red). Pictures show representative astrocytes within the coronal sections of STR. (F) Quantification of HO-1 expressing astrocytes. GFAP-stained cells were classified in the green channel as nonstained and HO-1stained astrocytes. Background fluorescence was taken as that of surrounding tissue as determined with the MCID program. Values indicate percentage of astrocytes expressing HO- $1 \pm$ SEM from 470 astrocytes (two mice) in saline-treated and 450 astrocytes (three mice) in SFN-treated mice. Asterisk denotes significant differences between treatments with $p<0.05$. (To see this illustration in color the reader is referred to the web version of this article at www.liebertonline.com/ars). 
mean $\pm S D$. One-way ANOVA followed by Bonferroni's post hoc test or unpaired Student's $t$ test was used to evaluate the statistical significance between investigated groups.

\section{Results}

SFN crosses the blood-brain barrier and upregulates Nrf2 in basal ganglia

Animals were i.p. injected either with saline or with SFN $(50 \mathrm{mg} / \mathrm{kg})$, and SFN levels were determined at the indicated time points in VMB and STR by HPLC. As shown in Figure
$1 \mathrm{~A}$ and $\mathrm{B}, \mathrm{SFN}$ was detected at both locations with maximal levels after $15 \mathrm{~min}$ and was still present after $60 \mathrm{~min}$. Then, we analyzed whether the amount of SFN that reaches the brain is sufficient to activate Nrf2. Striatal protein lysates of SFN-treated $\mathrm{Nrf2}{ }^{+/+}$and $\mathrm{Nrf}^{-/-}$mice were immunoblotted with anti-Nrf2 antibody. As shown in Figure $1 \mathrm{C}$ and $\mathrm{D}$, already at $1 \mathrm{~h}$ after i.p. injection, SFN provoked about sixfold increase in Nrf2 protein levels in the STR of $\mathrm{Nrf2} 2^{+/}$mice and its expression gradually decreased reaching basal levels within $4 \mathrm{~h}$. Importantly, Nrf2 ${ }^{-/-}$mice submitted to the same protocol exhibited neither basal nor
A

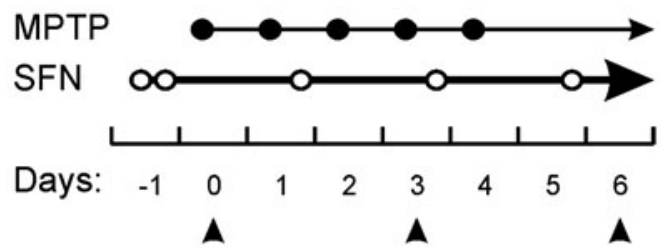

- Time-point for MPTP treatment

- Time-point for SFN treatment

A Time-point for sacrificing the animals
B

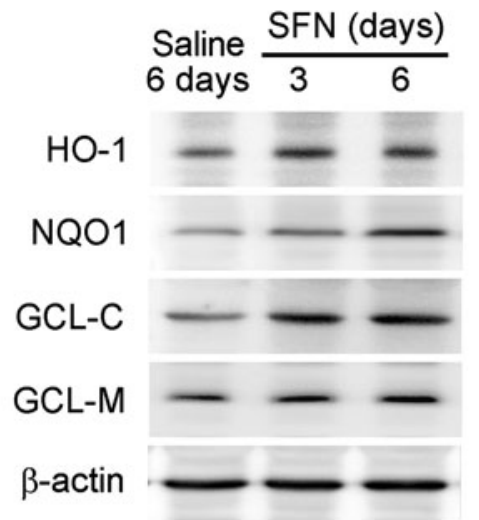

C

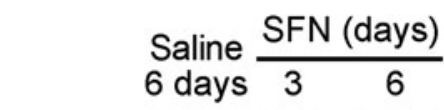

HO-1

NQO1

GCL-C

GCL-M

$\beta$-actin
VMB
D

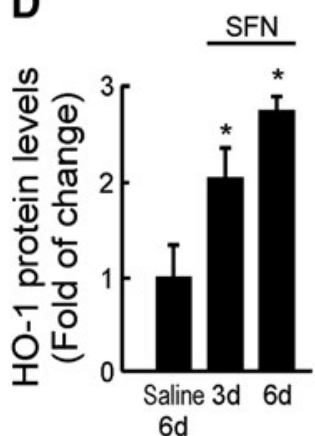

H

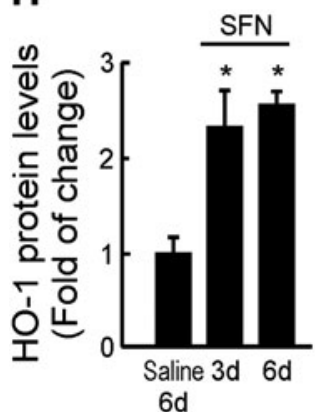

E

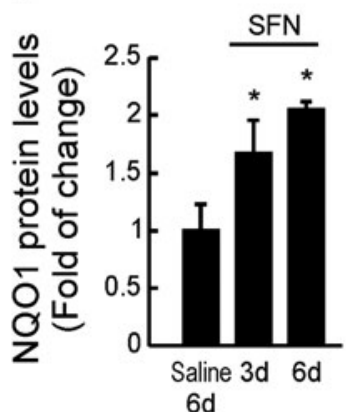

I

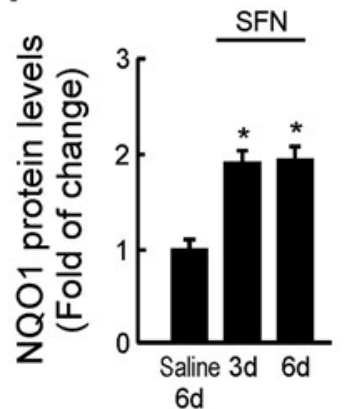

$\mathbf{F}$

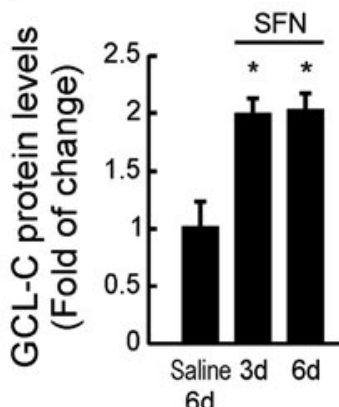

$\mathbf{J}$

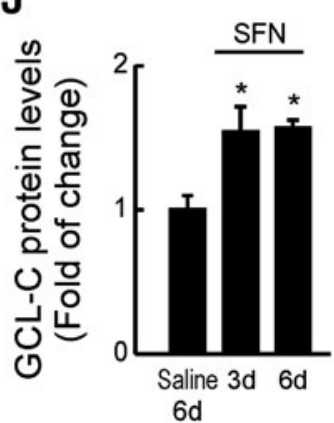

G

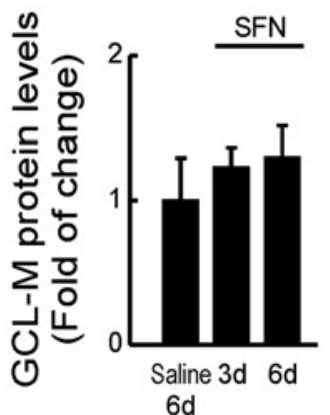

$\mathbf{K}$

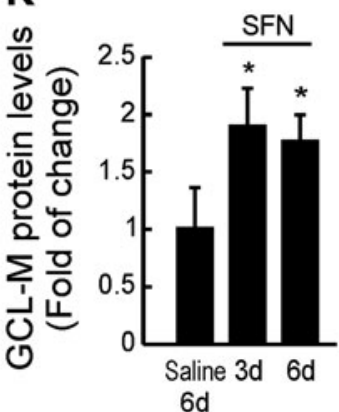

FIG. 3. Protocol for induction of a phase II response in STR and VMB. (A) Combined protocol of SFN and MPTP delivery. SFN and MPTP were given i.p. at doses of 50 and $30 \mathrm{mg} / \mathrm{kg}$, respectively, at the indicated days (filled circles for MPTP injections and empty circles for SFN injections). Animals were sacrificed at days 0,3 , and 6. (B, C) Immunoblots of STR and VMB protein extracts, respectively, blotted with anti-HO-1, anti-NQO1, anti- $\gamma$-glutamyl cysteine ligase-catalytic subunit (GCL-C), anti- $\gamma$-glutamyl cysteine ligase-modulator subunit (GCL-M), and anti- $\beta$-actin antibodies. (D, E, F, G) Densitometric quantification from representative immunoblots of STR lysates after normalization with $\beta$-actin. (H, I, J, K) Densitometric quantification from representative immunoblots of VMB lysates after normalization with $\beta$-actin. Values represent mean \pm SD of three to five mice per group and per time point. Asterisks denote significant differences between treatments with $p<0.05$. 
SFN-induced Nrf2 expression (Fig. 1C). Therefore, we conclude that SFN crosses the blood brain barrier and upregulates striatal Nrf2.

Next, we determined whether Nrf2 deficiency or SFN treatment might interfere with the normal in vivo conversion of MPTP to its active principle, $\mathrm{MPP}^{+}$(Fig. 1E). We analyzed protein levels of MAO-B, an enzyme that converts MPTP to $\mathrm{MPP}^{+}$, and DAT, which mediates $\mathrm{MPP}^{+}$uptake by nigral dopaminergic neurons. $\mathrm{Nrf} 2^{+/+}$and $\mathrm{Nrf} 2^{-/-}$mice were injected i.p. either with saline or with $50 \mathrm{mg} / \mathrm{kg} \mathrm{SFN}$; and
A

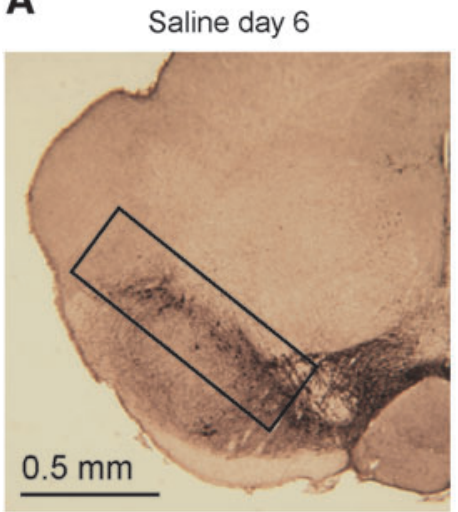

SFN day 6

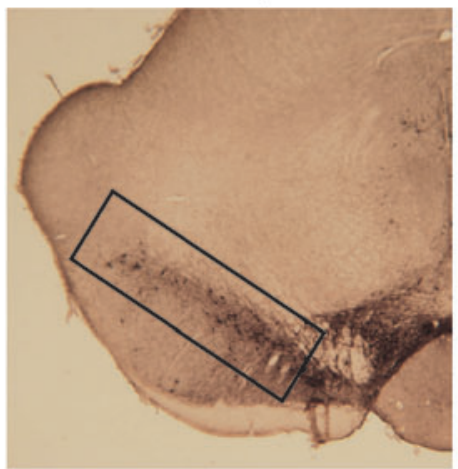

B

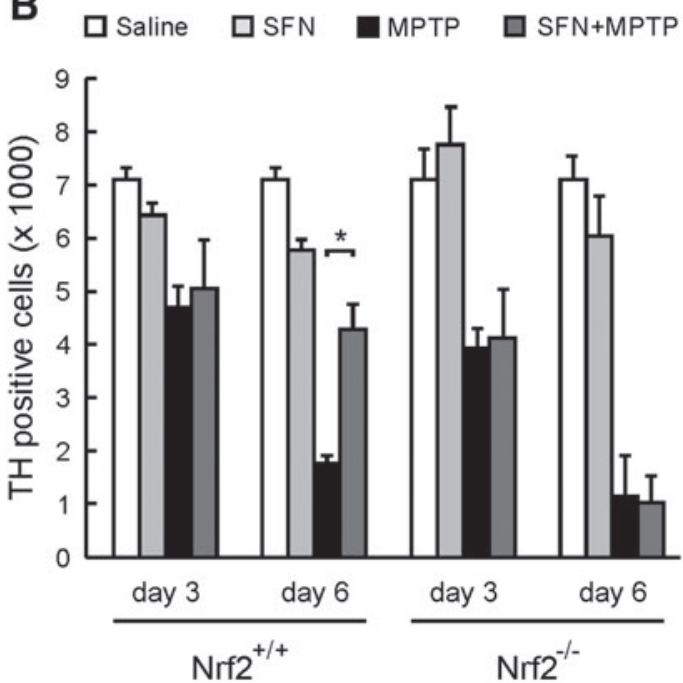

MPTP day 3

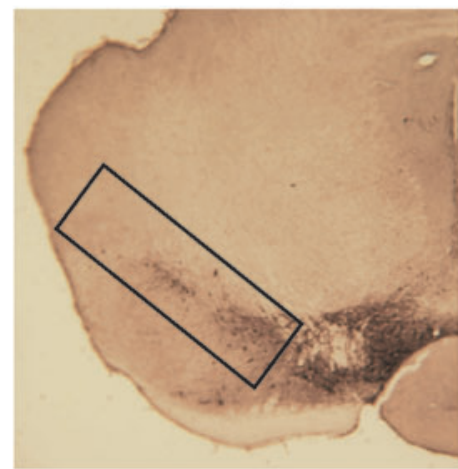

SFN+MPTP day 3

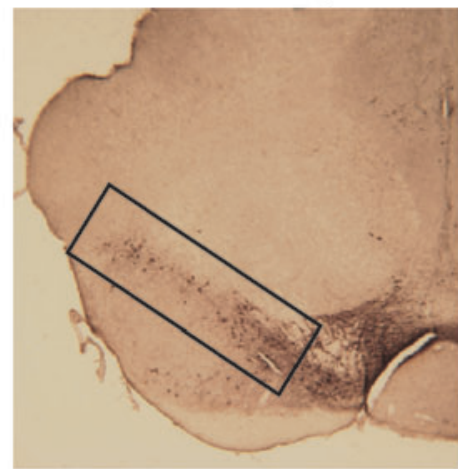

C Saline

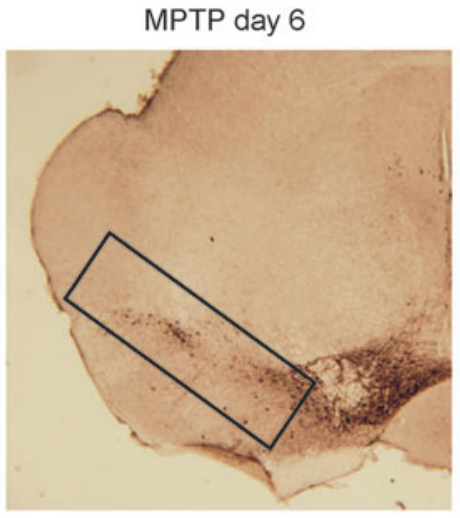

SFN+MPTP day 6

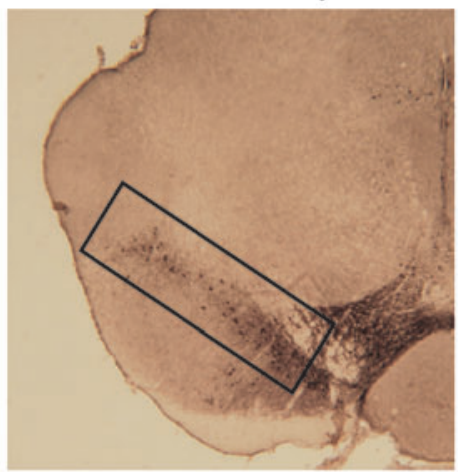

SFN

MPTP

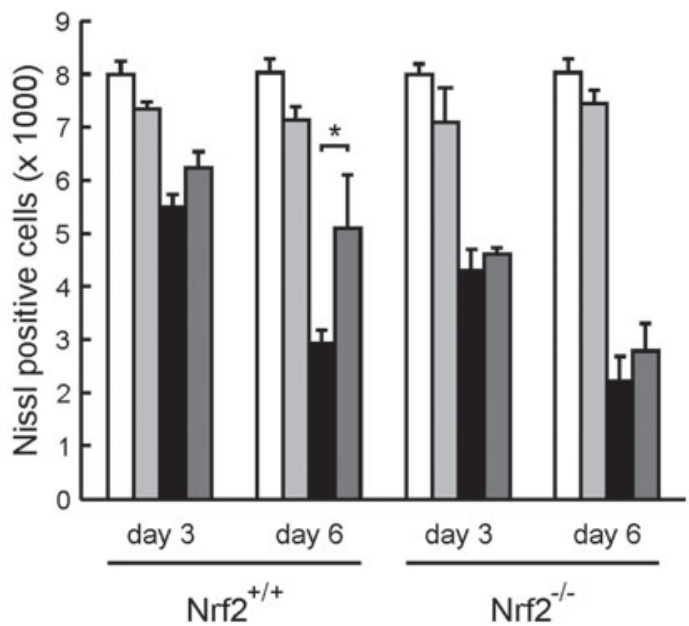

FIG. 4. SFN protects against MPTP-induced neurotoxicity in the SN of Nrf2 ${ }^{+/+}$but not Nrf2 $2^{-/-}$mice. Mice were submitted to the combined protocol of SFN and MPTP delivery. (A) Immunohistochemistry with anti-tyrosine hydroxylase (TH) antibody in Nrf2 ${ }^{+/+}$mice in $30 \mu$ m-thick coronal sections of VMB. Rectangles indicate SN. (B) Stereological quantification of TH-immunoreactive neurons in SN of Nrf2 ${ }^{+/+}$and $\mathrm{Nrf}^{-/-}$mice. (C) Stereological quantification of Nissl-positive neurons in SN of $\mathrm{Nrf} 2^{+/+}$and $\mathrm{Nrf} 2^{-/-}$mice. Values represent mean $\pm \mathrm{SD}$ of three to five mice per group and per time point. Asterisks denote significant differences between treatments with $p<0.05$. (To see this illustration in color the reader is referred to the web version of this article at www.liebertonline.com/ars). 
striatal protein lysates were analyzed after $16 \mathrm{~h}$. MAO-B and DAT levels were similar among genotypes and treatments. In additional experiments, we analyzed the conversion of MPTP to $\mathrm{MPP}^{+}$by HPLC (Fig. 1F, G). Striatal $\mathrm{MPP}^{+}$levels were very similar in saline- and SFN-treated mice at 30 and 60 min after injection of $30 \mathrm{mg} / \mathrm{kg}$ MPTP. Moreover, STR or VMB levels of $\mathrm{MPP}^{+}$were also similar in $\mathrm{Nrf} 2^{+/+}$and $\mathrm{Nrf} 2^{-/-}$mice at $30 \mathrm{~min}$ after MPTP injection. These results indicate that neither Nrf2 deficiency nor SFN treatment interfere with the MPTP conversion to $\mathrm{MPP}^{+}$.
A

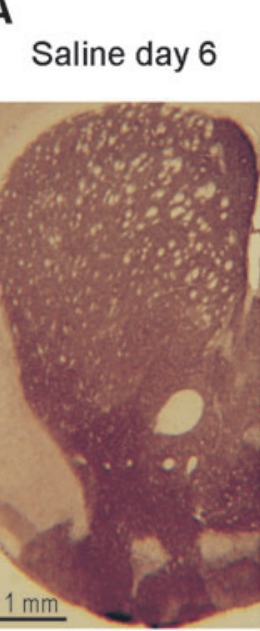

SFN

day 6

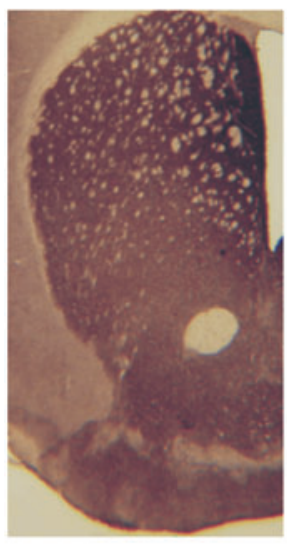

E

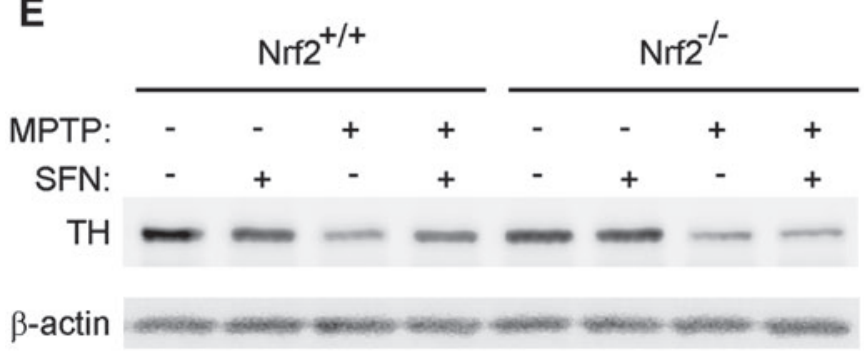
day 6
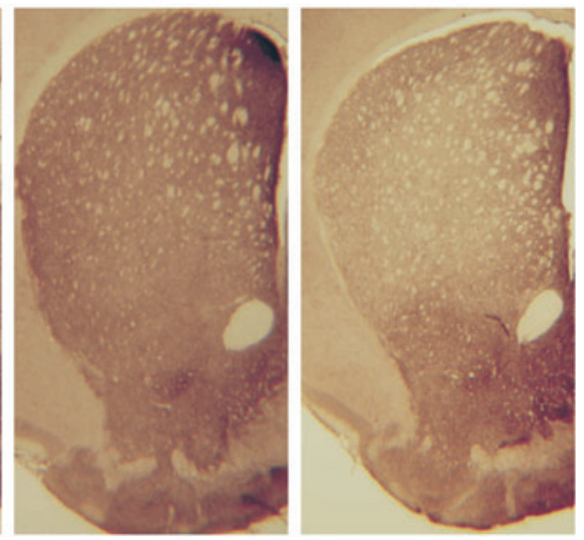

B

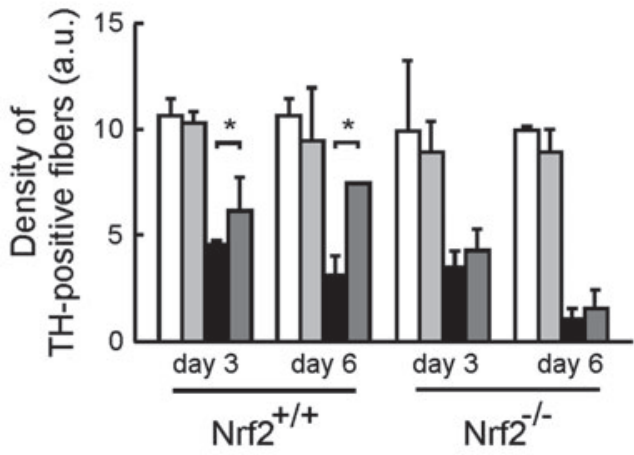

C

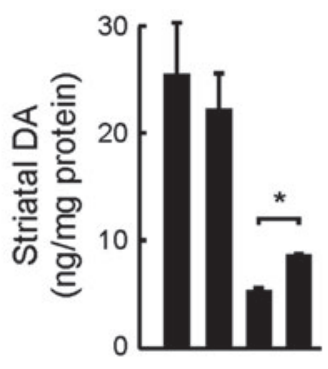

MPTP: - - + +

SFN: -+-+

D

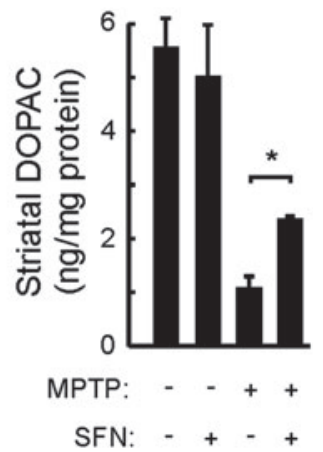

$\mathbf{F}$

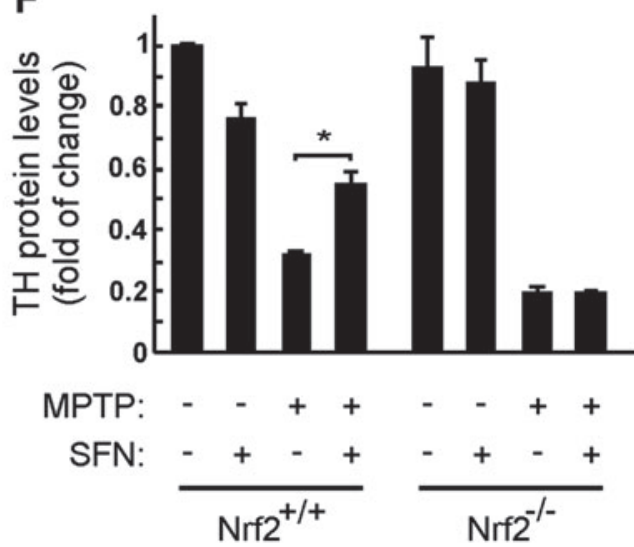

FIG. 5. SFN protects against MPTP-induced neurotoxicity in STR of $\mathrm{Nrf}^{+/+}$but not Nrf2 ${ }^{-/-}$mice. Animals were submitted to the combined protocol of SFN and MPTP delivery. (A) Immunohistochemistry with anti-TH antibody. Pictures show $30 \mu \mathrm{m}$-thick coronal sections of STR of Nrf2 ${ }^{+/+}$mice. (B) Densitometric quantification of TH-positive fibers in $\mathrm{Nrf2} 2^{+/+}$and Nrf2 $2^{-/-}$mice. (C, D) High-performance liquid chromatography determination of dopamine (DA) and dihydroxyphenylacetic acid (DOPAC), respectively, in STR of $\mathrm{Nrf}^{+/+}$mice. (E) Immunoblots of striatal protein extracts from $\mathrm{Nrf} 2^{+/+}$and Nrf2 ${ }^{-/-}$mice blotted with anti-TH and anti- $\beta$-actin antibodies. (F) Densitometric quantification from representative immunoblots after normalization to $\beta$-actin. Values represent mean \pm SD of three to five mice per group and per time point. Asterisks denote significant differences between treatments with $p<0.05$. (To see this illustration in color the reader is referred to the web version of this article at www.liebertonline.com/ars). 


\section{SFN activates the phase II response in STR}

To determine the relevance of Nrf2 activation, we analyzed the protein levels of two typical Nrf2-regulated phase II enzymes, HO-1 and NQO1, in Nrf2 ${ }^{+/+}$and $\mathrm{Nrf}^{-/-}$mice at $16 \mathrm{~h}$ after SFN administration. SFN was able to induce about twofold increase of HO-1 and NQO1 in STR (Fig. 2A, B) and VMB (Fig. 2C, D) of Nrf2 ${ }^{+/+}$mice but not in their Nrf2 $2^{-/-}$ littermates. Therefore, SFN activates the antioxidant response in STR and VMB in an Nrf2-dependent manner.

To identify the cell types that might be responding to SFN, we performed double immunofluorescence for $\mathrm{HO}-1$ and the markers tyrosine hydroxylase (TH) (dopaminergic neurons), tomato lectin (endothelial cells), Iba-1(microglia), or GFAP (astrocytes). As shown in Supplementary Figure S2, endothelial cells and microglia had very low levels of HO-1 that were not substantially changed by SFN. Dopaminergic neurons exhibited a diversified pattern of $\mathrm{TH}$ staining and HO-1 staining that was not altered by SFN. Finally, as shown also in Figure 2E and, some astrocytes from saline inoculated mice exhibited a very weak HO-1 staining that was increased in the
SFN-treated mice. These results point the astrocytes as the main SFN responsive cells in the basal ganglia.

\section{Design of a protocol for sustained induction of phase II enzymes by SFN in the basal ganglia}

Several schedules and doses of SFN were tested to achieve a steady increase in the levels of phase II enzymes in STR and VMB (data not shown). Since SFN did not show evidence of toxicity even at the very high dose of $50 \mathrm{mg} / \mathrm{kg}$, for the purpose of this study we used the protocol depicted in Figure 3A. This protocol consisted of two i.p. injections of SFN ( $50 \mathrm{mg} / \mathrm{kg}$, 8-h interval, day -1), which, on the next day (day 0), led to increased HO-1 and NQO1 protein levels (Fig. 2). We have previously observed that such upregulated HO1 protein levels remain elevated for at least $48 \mathrm{~h}$ (11). Therefore, the reinforcement doses of SFN were administered at days 1,3 , and 5 . MPTP $(30 \mathrm{mg} / \mathrm{kg})$ was injected i.p. for 5 consecutive days starting at day 0 . Under these conditions, SFN elicited about twofold increase in the expression of STR and VMB phase II enzymes HO-1, NQO1, GCL-M,
A Saline
day 6

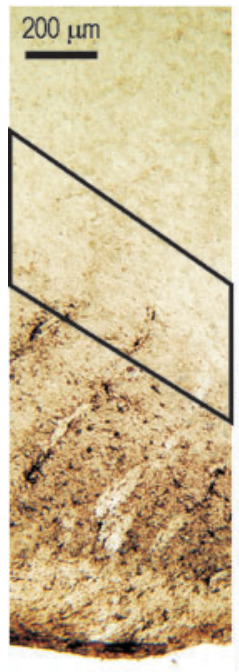

MPTP

day 3

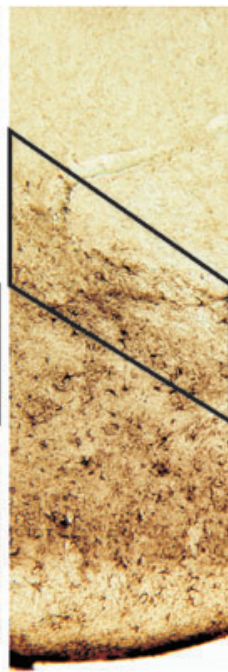

C

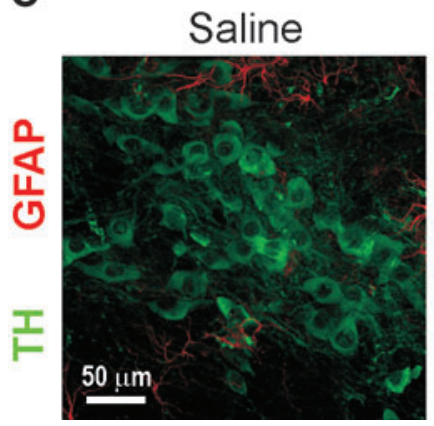

MPTP

day 6

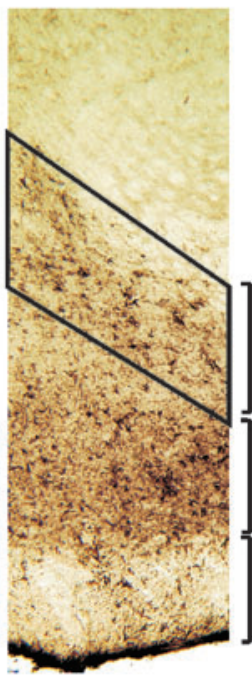

B
SFN+MPTP day 3

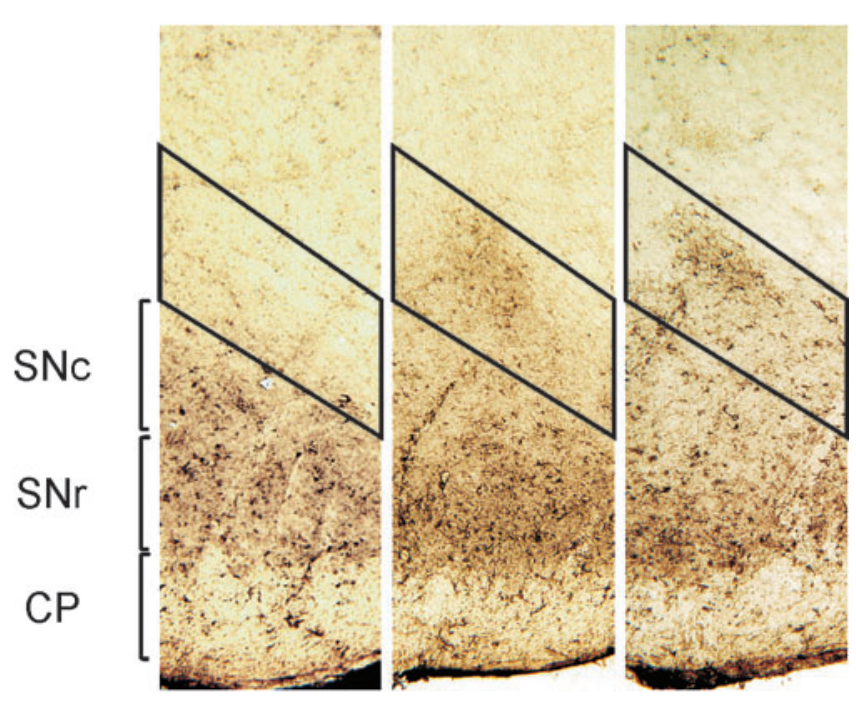

SFN+MPTP day 6

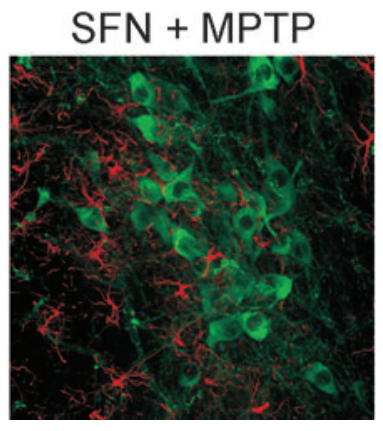

FIG. 6. SFN prevents against MPTP-induced astrogliosis in VMB. Wild-type mice were submitted to the combined protocol of SFN and MPTP delivery. (A, B) Immunohistochemistry with anti-GFAP antibody. Pictures show coronal sections of VMB. The outlined area indicates the substantia nigra pars compacta $(\mathrm{SNc})$ located above the substantia nigra pars reticulata $(\mathrm{SN} r)$ and cerebral peduncle $(\mathrm{CP})$. (C) Double immunofluorescence with anti-TH (green) and anti-GFAP (red) antibodies from the SN region at day 6. Pictures are representative of three to five animals per group and per time point. (To see this illustration in color the reader is referred to the web version of this article at www.liebertonline.com/ars). 
and GCL-C at days 3 and 6, compared with control untreated animals (Fig. 3).

\section{SFN is neuroprotective against MPTP-induced dopaminergic neuron damage}

Mice were submitted to MPTP or SFN according to the protocol shown in Figure $3 \mathrm{~A}$ and $30 \mu \mathrm{m}$-thick sections from VMB were used for TH-immunohistochemistry. MPTP-treated mice exhibited a substantial loss of $\mathrm{TH}$ immunoreactivity in VMB that was perceptible already at day 3 and even more exaggerated at day 6 (Fig. 4A). Concurrently, stereological count of TH-positive and Nissl-positive cells within the area outlined in Figure 4A indicated a reduction of dopaminergic neurons of about $30 \%$ at day 3 and about $60 \%$ at day 6 in comparison to the saline-treated animals (Fig. 4B, C). Interestingly, SFN partially rescued both MPTP-induced loss of $\mathrm{TH}$-staining and dopaminergic neuron abundance, particularly at day 6. By contrast, SFN did not protect significantly against dopaminergic neuron loss in the Nrf2-deficient mice.

Striatal dopaminergic fibers were also protected by SFN in wild-type mice (Fig. 5A, B). Striatal DA and DOPAC levels were analyzed by HPLC (Fig. 5C, D). The MPTP lesion removed nearly $80 \%$ of striatal DA and DOPAC. By contrast, SFN led to a modest but significant rescue of both DA and DOPAC levels.
A Saline
day 6

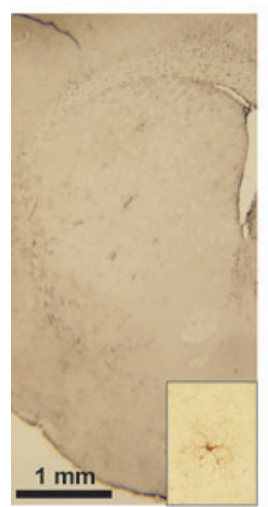

MPTP day 3

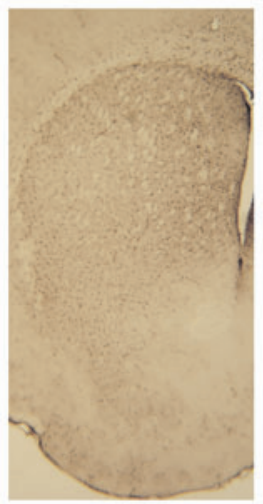

C

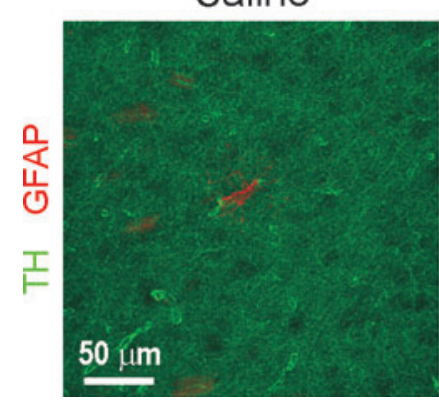

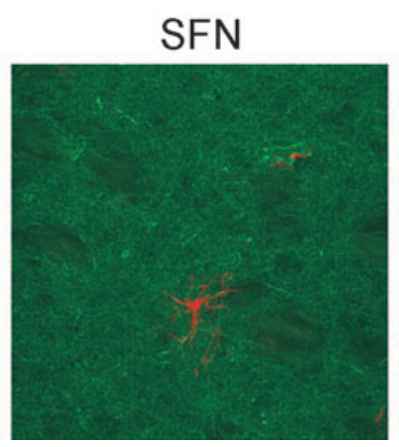

To further exclude off-target effects of SFN in STR, we submitted $\mathrm{Nrf2}^{-/-}$mice and $\mathrm{Nrf2}^{+/+}$littermates to the combined SFN/MPTP protocol. As for neuron bodies in VMB (Fig. 4B, C), TH-stained fibers were not protected by SFN in the Nrf2-knockout mice (Fig. 5B). Also, we analyzed TH protein levels by immunoblot (Fig. 5E, F). MPTP elicited a $68 \%$ and $82 \%$ reduction of $\mathrm{TH}$ in $\mathrm{Nrf} 2^{+/+}$and $\mathrm{Nrf} 2^{-/-}$mice, respectively, but more importantly, although SFN rescued TH protein levels to more than $50 \%$ in $\mathrm{Nrf2}^{+/+}$mice, it did not have a any consequence on the $\mathrm{Nrf2}^{-/-}$mice. Therefore, these results indicate that the protective effect of SFN against MPTP-induced nigrostriatal damage is provided by Nrf2 and we focused the rest of this study on wild-type mice.

\section{SFN attenuates MPTP-induced astrogliosis}

One of the hallmarks of the inflammatory response to MPTP is the increased number of astrocytes within the nigrostriatal tract, STR and SN. Therefore, astrogliosis was analyzed in coronal sections of VMB immunostained with anti-GFAP antibody (Fig. 6A, B). We observed radial astroglia in the brain peduncles and there was very little immunoreactivity in the outlined region of substantia nigra of salineand SFN-treated mice. As expected, in MPTP-treated mice we detected an increased number of astrocytes in this site (Fig. 6A). GFAP immunoreactivity after MPTP and SFN treatment

\section{B}

SFN day 6

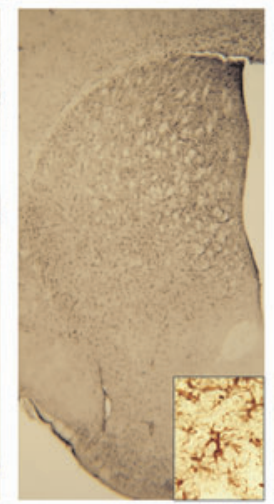

SFN+MPTP day 3
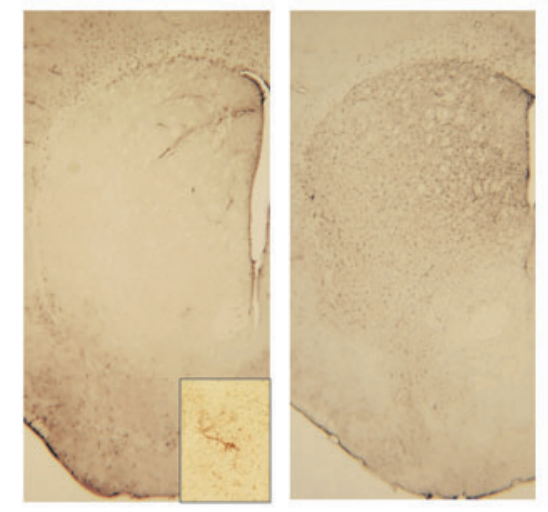

SFN+MPTP day 6

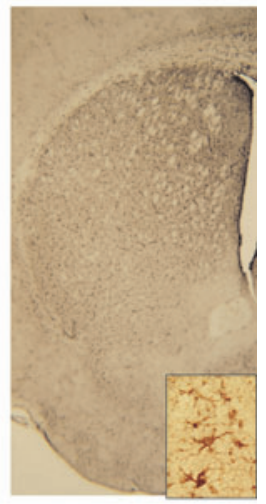

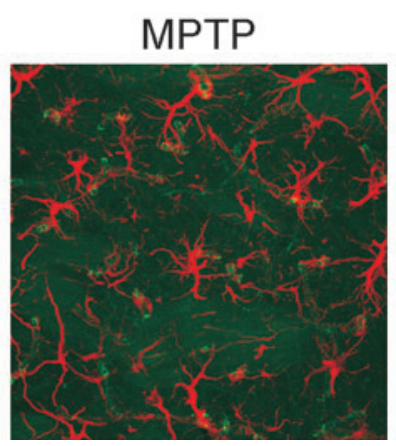

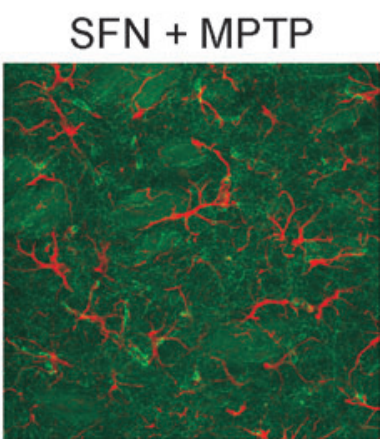

FIG. 7. SFN reduces the MPTP-induced astrogliosis in STR. Wild-type mice were submitted to the combined protocol of SFN and MPTP delivery. (A, B) Immunohistochemistry with anti-GFAP antibody. Pictures show coronal sections of STR. Insets show high-magnification STR fields with resting (Saline day 6) and activated (MPTP day 6) astrorytes. (C) Double immunofluorescence with anti-TH (green) and anti-GFAP (red) antibodies from STR at day 6. Pictures are representative of three to five animals per group and per time point. (To see this illustration in color the reader is referred to the web version of this article at www.liebertonline.com/ars). 
was lower when compared with MPTP-injected animals at days 3 and 6 (Fig. 6B). To further confirm this observation, we performed double immunofluorescence staining with anti-TH and anti-GFAP antibodies in VMB sections from day 6 (Fig. 6C). In saline- and SFN-treated animals, the SN was occupied by many TH-positive neurons and very few astrocytes. By contrast, in MPTP-treated mice we found lower abundance of TH-positive neurons and many astrocytes forming the glial scar. Interestingly, in animals submitted to both SFN and MPTP injections, we found an intermediate pattern with more dopaminergic neurons and fewer astrocytes.

The MPTP-induced astrogliosis in STR was also attenuated by SFN (Fig. 7A, B). Immunohistochemical staining with antiGFAP antibodies revealed just a few astrocytes in STR of saline or SFN-treated animals. These astrocytes exhibited a small body and very thin branches, evidencing a resting state (Fig. 7A, B, insets). By contrast, STR from MPTP-treated mice at days 3 and 6 was crowded with astrocytes that at higher magnification demonstrated thick bodies and branches, indicating their activation state (Fig. 7A). Animals submitted to both SFN and MPTP injections presented also high abundance of STR astrocytes, but they were not as abundant as in the MPTPtreated mice (Fig. 7B). Further confirmation of the inhibitory effect of SFN on STR astrogliosis was obtained by double immunofluorescence of sections from day 6 stained with anti-TH and anti-GFAP antibodies (Fig. 7C). Saline- and SFN-treated animals exhibited a reticulated anti- $\mathrm{TH}$ staining pattern, corresponding to dopaminergic fibers, and a few scattered astrocytes with resting morphology. As expected, MPTP-lesioned mice exhibited weak immunolabeling for TH-positive nerve fibers and a larger number of astrocytes. Finally, mice submitted to both MPTP and SFN presented an intermediate pattern, with more TH fibers and fewer astrocytes than MPTPtreated animals. Overall, these results indicate that Nrf2 activation by SFN decreases astrogliosis in response to MPTP.

\section{SFN attenuates MPTP-induced microgliosis}

We examined the levels of microgliosis using Iba-1 immunoreactivity (Fig. 8A, B). In saline- and SFN-treated mice, we

\section{A}

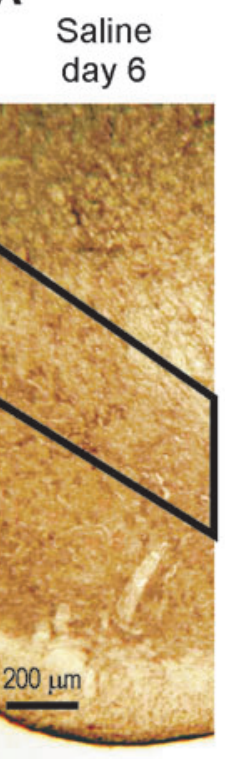

MPTP day 3

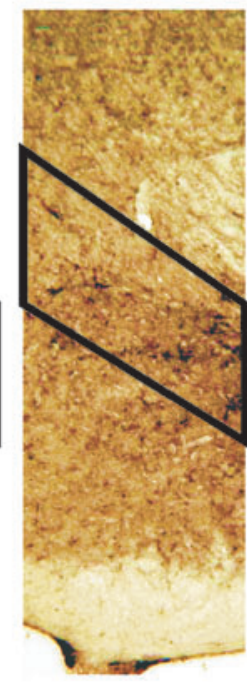

MPTP day 6

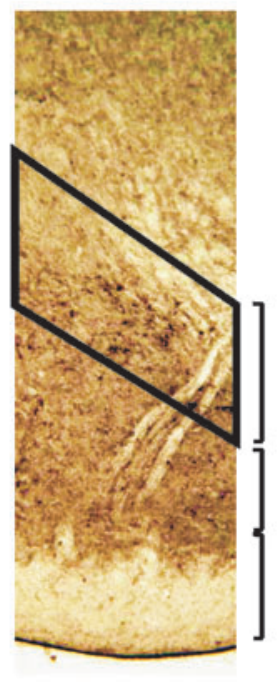

B

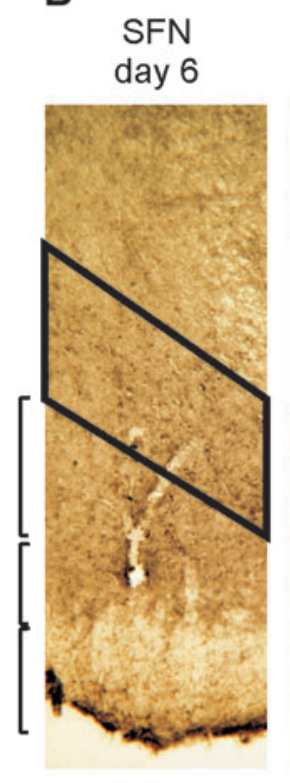

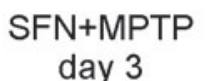

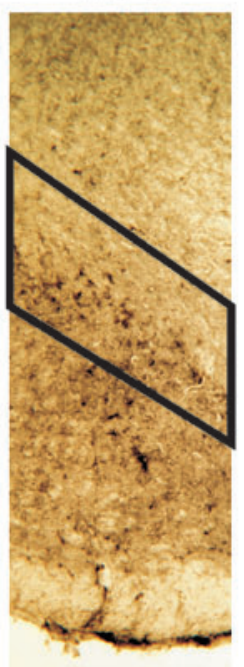

SFN+MPTP day 6

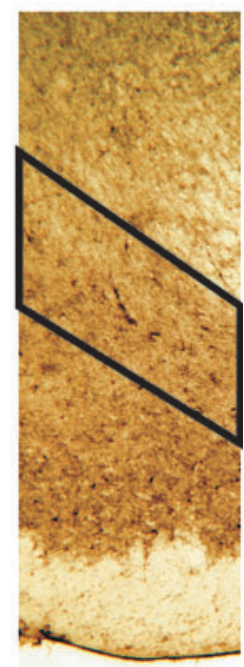

C

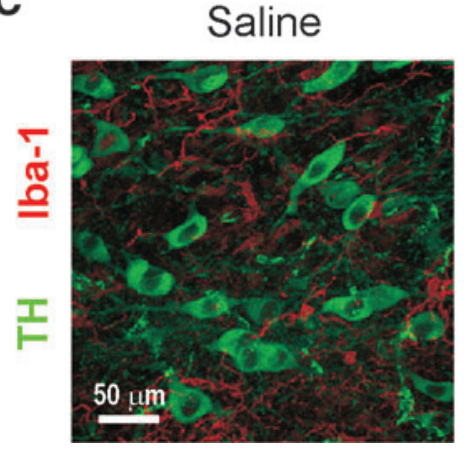

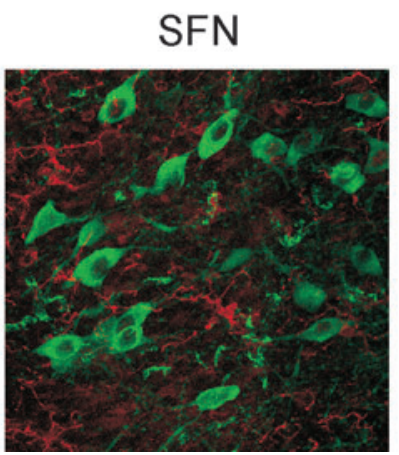
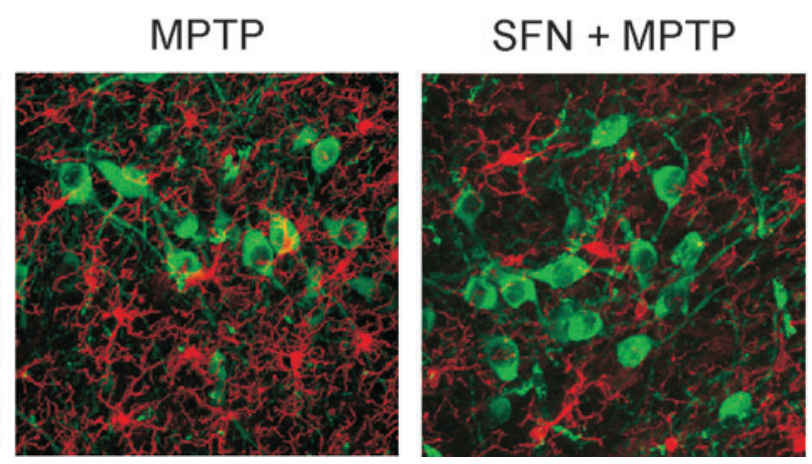

FIG. 8. SFN prevents against MPTP-induced microgliosis in VMB. Wild-type mice were submitted to the combined protocol of SFN and MPTP delivery. (A, B) Immunohistochemistry with anti-Iba-1 antibody. Pictures show coronal sections of VMB. The outlined area indicates the substantia nigra pars compacta $(\mathrm{SNc})$ located above the substantia nigra pars reticulata $(\mathrm{SNr})$ and cerebral peduncle $(\mathrm{CP})$. (C) Double immunofluorescence with anti-TH (green) and anti-Iba-1 (red) antibodies from the SN region at day 6. Pictures are representative of three to five animals per group and per time point. (To see this illustration in color the reader is referred to the web version of this article at www.liebertonline.com/ars). 
could barely detect microglia in the outlined area of VMB corresponding to SN. By contrast, MPTP-treated mice exhibited strong increase in Iba- 1 immunoreactive cells at days 3 and 6. In mice submitted to both MPTP and SFN injections, microglial activation was more moderate, particularly at day 6 . Further evidence for microglial activation in the SN was obtained by double immunofluorescence of $\mathrm{VMB}$ sections stained with anti-TH and anti-Iba1 antibodies (Fig. 8C). Saline- and SFN-treated mice exhibited a similarly high abundance of THpositive dopaminergic neurons and very few microglial cells. MPTP treatment led to dopaminergic neurons loss and strong microgliosis. Finally, animals submitted to combined MPTP and SFN delivery exhibited an intermediate pattern with more dopaminergic neurons and fewer microglia.

Similar analysis was performed in STR (Fig. 9A, B). At high magnification, we observed just a few microglial cells of either saline- or SFN-treated mice. Exposure to MPTP led to a mild increase in Iba-1 expressing microglia and this tendency was partially blocked by SFN. Again, these results were further corroborated by double immunofluorescence in STR sections stained with anti-TH and anti-Iba1 antibodies (Fig. 9C). The reduction in dopaminergic fibers induced by MPTP was associated with an increase in Iba1-positive microglia. By contrast, in the presence of SFN there was a lower reduction of dopaminergic fibers and a lower microgliosis. These results indicate that the loss of nigrostriatal DA neurons in response to MPTP is accompanied by increased microgliosis and that this situation is partially reversed by SFN.

A

Saline day 6

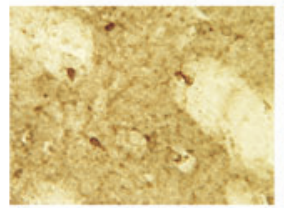

B

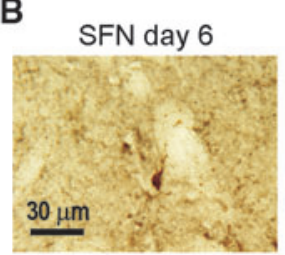

C Saline
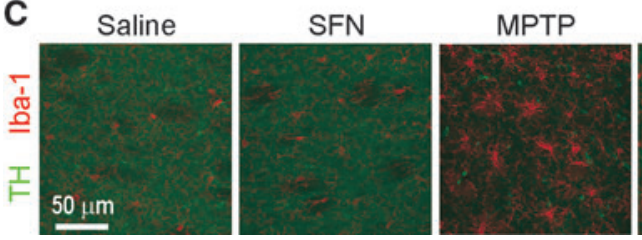

SFN + MPTP

FIG. 9. SFN reduces the MPTP-induced microgliosis in STR. Wild-type mice were submitted to the combined protocol of SFN and MPTP delivery. (A, B) Immunohistochemistry with anti-Iba-1 antibody. Pictures show coronal sections of STR. (C) Double immunofluorescence with antiTH (green) and anti-Iba-1 (red) antibodies from STR at day 6. Pictures are representative of three to five animals per group and per time point. (To see this illustration in color the reader is referred to the web version of this article at www .liebertonline.com/ars).

\section{SFN attenuates the pro-inflammatory} response caused by MPTP

One of the consequences of induced gliosis is the secretion of pro-inflammatory mediators such as interleukins among others in the brain parenchyma. We examined the levels of two classical pro-inflammatory mediators, interleukin-6 (IL-6) and tumor necrosis factor- $\alpha$ (TNF- $\alpha$ ), in STR (Fig. 10A, C). Messenger RNA analysis by q quantitative PCR revealed that both cytokines are upregulated on MPTP exposure, an effect partially inhibited after SNF treatment. Similarly, striatal protein extracts from MPTP-injected mice immunobloted with anti-IL-6 and anti-TNF- $\alpha$ antibodies exhibit increased levels of both cytokines (Fig. 10B, D). Again, SFN attenuated the MPTP-induced increase in IL- 6 and TNF- $\alpha$ proteins. Taken together, these results suggest that SFN attenuates the MPTPinduced production of pro-inflammatory mediators in basal ganglia.

\section{Discussion}

In this study, we activated pharmacologically the transcription factor Nrf2 in the brain to determine its role in neuroprotection and modulation of neuroinflammation in an experimental model of PD. For this purpose, we used the potent Nrf2 inducer SFN $(6,8,18)$. Given i.p. at a dose of $50 \mathrm{mg} / \mathrm{kg}$, SFN was found in STR and VMB, two locations involved in the motor pathology of PD. This concentration was selected after trial and error of several other conditions and is compatible with low mortality of mice submitted to the sub-acute model of MPTP (30 mg/kg MPTP per i.p. injection, 5 consecutive days).

SFN levels detected in the STR were sufficient to increase striatal Nrf2 protein for $2 \mathrm{~h}$. Moreover, two i.p. injections of SFN $(50 \mathrm{mg} / \mathrm{kg}$ ) resulted in upregulation of the phase II enzymes such as HO-1 and NQO1 by about two- to threefold. This low over-expression was probably an advantage of this protocol, because very high phase II enzymes levels may have detrimental effects (19). Thus, an increase on HO-1 of this magnitude in transgenic mice was neuroprotective in a model of glutamate induced excitotoxicity (3), whereas high HO-1 over-expression promoted oxidative mitochondrial damage in rat astrocytes by a mechanism that is probably mediated by ferrous iron (29). Of note, wild-type and HO-1deficient mice exhibit similar iron levels in VMB when they are treated with MPTP (9). Therefore, iron accumulation in the parkinsonian brain may be more associated with iron clearance mechanisms such as the divalent metal transporter, ferritin-mediated cellular export, transferring sequestration, or with iron supply mechanisms by lactoferrin $(27,28)$ rather than with heme degradation by HO-1. Consequently, pharmacological targeting of Nrf2 may be a feasible therapy excluding the concern about HO-1 mediated toxicity. Other Nrf2-regulated genes might be relevant in PD therapy including NQO1 and enzymes related to glutathione synthesis and usage. Supplementary Figure S1 shows the role of some phase II enzymes in oxidant protection of dopaminergic neurons.

All nerve cells analyzed, including microglia, astroglia, endothelium, and neurons, have a functional Nrf2-dependent phase II response in vitro (data not shown; (7, 11, 31, 35). Therefore, we rationed that all these cell types would respond similarly to SFN induction in vivo. Also, since the increase in 

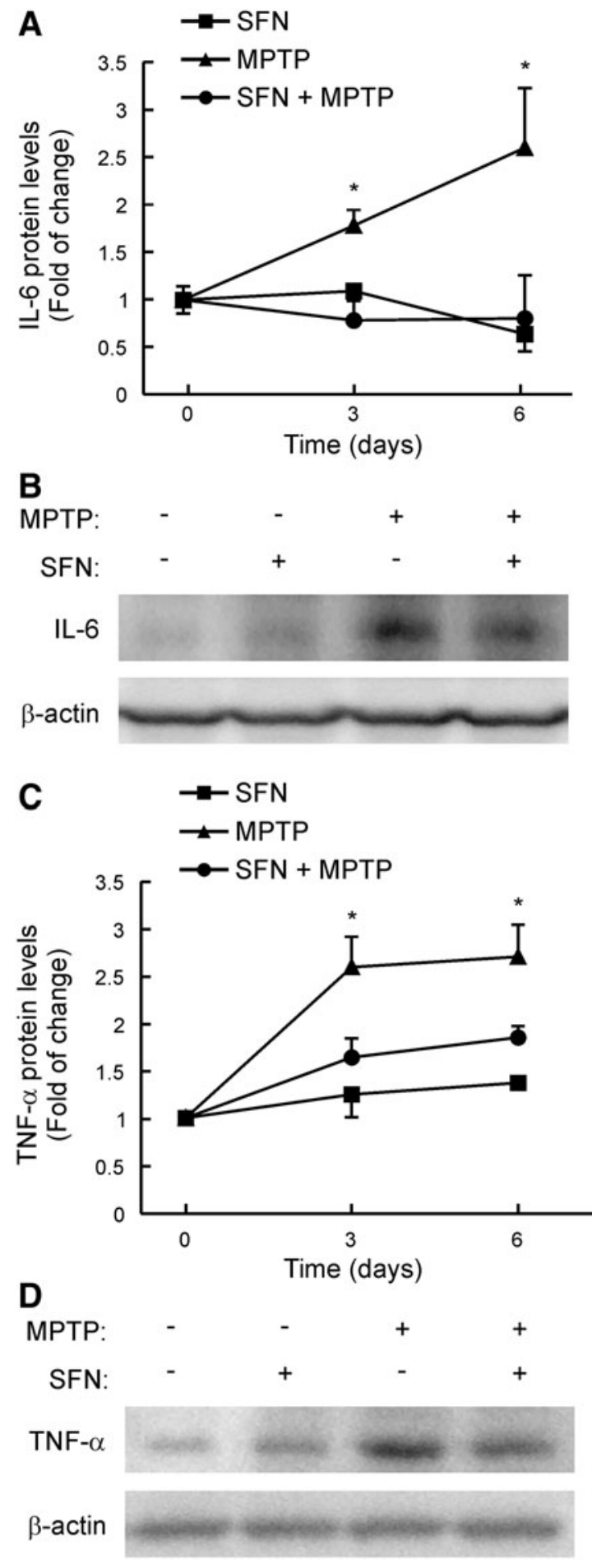

FIG. 10. SFN reduces the pro-inflammatory response induced by MPTP in STR. Wild-type mice were submitted to the combined protocol of SFN and MPTP delivery. (A) IL-6 mRNA levels determined by quantitative polymerase chain reaction. (B) Immunoblot of striatal protein extracts blotted with anti-IL-6 antibody. (C) TNF- $\alpha$ mRNA levels determined by quantitative polymerase chain reaction. (D) Immunoblot of striatal protein extracts blotted with anti-TNF- $\alpha$ antibody. Values represent mean \pm SD of three to five mice per group and per time point. Asterisks denote significant differences between treatments with $p<0.05$. phase II enzymes HO-1 and NQO1 was modest in immunoblots, we did not expect to see a clear increase in HO-1 protein levels associated with specific cell types. However, we found that HO-1 was upregulated in STR astrocytes after SFN treatment, suggesting that this cell type is more sensitive to phase II induction. Therefore, although it is possible that a low level of phase II upregulation in all nerve cell types might participate in brain modulation, at least the astrocytes should have a relevant role either by increasing their nurturing effect toward neurons or as immune modulators. This observation is in line with another study reporting that Nrf2 expression restricted to astrocytes is sufficient to protect against MPTPinduced toxicity (4).

Several genomics analyses have been conducted for the past 10 years to identify Nrf2-regulated genes, and so far there is no evidence that those involved in MPTP metabolism might be targets of Nrf2. Concordantly, wild-type and the Nrf2knockout mice as well as saline- and SFN-treated mice exhibited similar levels of MAO-B and DAT. Further, striatal $\mathrm{MPP}^{+}$levels did not differ between $\mathrm{Nrf} 2^{+/+}$mice and Nrf2 $2^{-/-}$littermates or between saline- and SFN-treated mice. These results exclude possible effects of Nrf2 and SFN that might be related to MPTP biotransformation or $\mathrm{MPP}^{+}$availability rather than with a direct effect on brain protection. Although Keap1/Nrf2 appear to be the preferred molecular target of SFN, its capacity to form adducts with other cellular macromolecules cannot be excluded. In fact, SFN has been reported to inhibit histone deacetylase (5) and participate in apoptosis and cell cycle arrest (26). Nevertheless, in this study we found that the SFN did not protect against MPTP-induced loss of $\mathrm{TH}$ immunoreactivity in the Nrf2-knockout mice, therefore, excluding off-target effects.

Nrf2 activation by SFN attenuated the nigrostriatal neurodegeneration induced by MPTP. Thus, the number of dopaminergic neurons (Nissl and $\mathrm{TH}$ positive) in the $\mathrm{SN}$ that survived MPTP was about $50 \%$ in the presence of SFN compared with MPTP-treated groups. Further, the density of TH-positive fibers in STR was protected by $20 \%$ compared with MPTP-treated mice. Striatal DA and DOPAC levels were also partially rescued by SFN but to a lesser, yet significant, extent than dopaminergic neuron loss. Although we do not have a convincing explanation, this small discrepancy may be related to compensatory mechanisms of the surviving neurons.

This preclinical study provides strong evidence to endorse a brain protective therapy in patients with PD by pharmacological targeting of the transcription factor Nrf2. Since SFN is a natural compound of many diets and because it is now being used in clinical trials for other pathologies $(18,21)$, it should be reasonable to use it as neuroprotective therapy together with DA replacement therapy. Issues to be solved include more specific pharmacokinetic and pharmacodynamic studies in humans and improvement of the route of administration.

\section{Acknowledgments}

This work was supported by a Target Validation Grant of the Michael J. Fox Foundation for Parkinson's Research and grant SAF2010-17822 from the Spanish Ministery of Science and Innovation. N.G.I. is recipient of a fellowship FPU from Universidad Autónoma of Madrid. 


\section{Author Disclosure Statement}

No competing financial interests exist.

\section{References}

1. Burton NC, Kensler TW, and Guilarte TR. In vivo modulation of the Parkinsonian phenotype by Nrf2. Neurotoxicology 27: 1094-100, 2006.

2. Cuadrado A, Moreno-Murciano P, and Pedraza-Chaverri J. The transcription factor Nrf2 as a new therapeutic target in Parkinson's disease. Expert Opin Ther Targets 13: 319-329, 2009.

3. Chen K, Gunter K, and Maines MD. Neurons overexpressing heme oxygenase- 1 resist oxidative stress-mediated cell death. J Neurochem 75: 304-13, 2000.

4. Chen PC, Vargas MR, Pani AK, Smeyne RJ, Johnson DA, Kan YW, and Johnson JA. Nrf2-mediated neuroprotection in the MPTP mouse model of Parkinson's disease: critical role for the astrocyte. Proc Natl Acad Sci U S A 106: 2933-8, 2009.

5. Dashwood RH and Ho E. Dietary agents as histone deacetylase inhibitors: sulforaphane and structurally related isothiocyanates. Nutr Rev 66 Suppl 1: S36-8, 2008.

6. Dinkova-Kostova AT and Talalay P. Direct and indirect antioxidant properties of inducers of cytoprotective proteins. Mol Nutr Food Res 52 Suppl 1: S128-38, 2008.

7. Hamdulay SS, Wang B, Birdsey GM, Ali F, Dumont O, Evans PC, Haskard DO, Wheeler-Jones CP, and Mason JC. Celecoxib activates PI-3K/Akt and mitochondrial redox signaling to enhance heme oxygenase-1-mediated antiinflammatory activity in vascular endothelium. Free Radic Biol Med 48: 1013-23, 2010.

8. Higgins LG, Kelleher MO, Eggleston IM, Itoh K, Yamamoto $\mathrm{M}$, and Hayes JD. Transcription factor Nrf2 mediates an adaptive response to sulforaphane that protects fibroblasts in vitro against the cytotoxic effects of electrophiles, peroxides and redox-cycling agents. Toxicol Appl Pharmacol 237: 267-80, 2009.

9. Innamorato NG, Jazwa A, Rojo AI, García C, FernándezRuiz J, Grochot-Przeczek A, Stachurska A, Jozkowicz A, Dulak J, and Cuadrado A. Different susceptibility to the Parkinson's toxin MPTP in mice lacking the redox master regulator Nrf2 or its target gene heme oxygenase-1. PLoS One 5: e11838, 2010.

10. Innamorato NG, Lastres-Becker I, and Cuadrado A. Role of microglial redox balance in modulation of neuroinflammation. Curr Opin Neurol 22: 308-14, 2009.

11. Innamorato NG, Rojo AI, Garcia-Yague AJ, Yamamoto M, de Ceballos ML, and Cuadrado A. The transcription factor Nrf2 is a therapeutic target against brain inflammation. J Immunol 181: 680-9, 2008.

12. Itoh $K$, Chiba $T$, Takahashi $S$, Ishii $T$, Igarashi $K$, Katoh $Y$, Oyake T, Hayashi N, Satoh K, Hatayama I, Yamamoto M, and Nabeshima Y. An Nrf2/small Maf heterodimer mediates the induction of phase II detoxifying enzyme genes through antioxidant response elements. Biochem Biophys Res Commun 236: 313-22, 1997.

13. Itoh $\mathrm{K}$, Ishii $\mathrm{T}$, Wakabayashi $\mathrm{N}$, and Yamamoto M. Regulatory mechanisms of cellular response to oxidative stress. Free Radic Res 31: 319-24, 1999.

14. Jenner P. Oxidative stress and Parkinson's disease. Handb Clin Neurol 83: 507-20, 2007.

15. Johnson DA, Andrews GK, Xu W, and Johnson JA. Activation of the antioxidant response element in primary cortical neuronal cultures derived from transgenic reporter mice. $J$ Neurochem 81: 1233-41, 2002.

16. Kensler TW, Wakabayashi N, and Biswal S. Cell survival responses to environmental stresses via the Keap1-Nrf2-ARE pathway. Annu Rev Pharmacol Toxicol 47: 89-116, 2007.

17. Lee JM, Calkins MJ, Chan K, Kan YW, and Johnson JA. Identification of the NF-E2-related factor-2-dependent genes conferring protection against oxidative stress in primary cortical astrocytes using oligonucleotide microarray analysis. J Biol Chem 278: 12029-38, 2003.

18. Li Y, Zhang T, Korkaya H, Liu S, Lee HF, Newman B, Yu Y, Clouthier SG, Schwartz SJ, Wicha MS, and Sun D. Sulforaphane, a dietary component of broccoli/broccoli sprouts, inhibits breast cancer stem cells. Clin Cancer Res 16: 2580-90, 2010.

19. Maher J and Yamamoto M. The rise of antioxidant signaling-the evolution and hormetic actions of Nrf2. Toxicol Appl Pharmacol 244: 4-15, 2010.

20. Marzec JM, Christie JD, Reddy SP, Jedlicka AE, Vuong $H$, Lanken PN, Aplenc R, Yamamoto T, Yamamoto M, Cho HY, and Kleeberger SR. Functional polymorphisms in the transcription factor NRF2 in humans increase the risk of acute lung injury. FASEB J 21: 2237-46, 2007.

21. Moon JK, Kim JR, Ahn YJ, and Shibamoto T. Analysis and anti-Helicobacter activity of sulforaphane and related compounds present in broccoli (Brassica oleracea L.) sprouts. J Agric Food Chem 58: 6672-7, 2010.

22. Ramsey $\mathrm{CP}$, Glass $\mathrm{CA}$, Montgomery MB, Lindl KA, Ritson GP, Chia LA, Hamilton RL, Chu CT, and Jordan-Sciutto KL. Expression of Nrf2 in neurodegenerative diseases. J Neuropathol Exp Neurol 66: 75-85, 2007.

23. Rojo AI, Cavada C, de Sagarra MR, and Cuadrado A. Chronic inhalation of rotenone or paraquat does not induce Parkinson's disease symptoms in mice or rats. Exp Neurol 208: 120-6, 2007.

24. Rojo AI, Innamorato NG, Martin-Moreno AM, De Ceballos ML, Yamamoto $\mathrm{M}$, and Cuadrado A. Nrf2 regulates microglial dynamics and neuroinflammation in experimental Parkinson's disease. Glia 58: 588-98, 2010.

25. Rojo AI, Montero C, Salazar M, Close RM, Fernandez-Ruiz J, Sanchez-Gonzalez MA, de Sagarra MR, Jackson-Lewis V, Cavada C, and Cuadrado A. Persistent penetration of MPTP through the nasal route induces Parkinson's disease in mice. Eur J Neurosci 24: 1874-84, 2006.

26. Roy SK, Srivastava RK, and Shankar S. Inhibition of PI3K/ AKT and MAPK/ERK pathways causes activation of FOXO transcription factor, leading to cell cycle arrest and apoptosis in pancreatic cancer. J Mol Signal 5: 10, 2010.

27. Salazar J, Mena N, Hunot S, Prigent A, Alvarez-Fischer D, Arredondo M, Duyckaerts C, Sazdovitch V, Zhao L, Garrick LM, Nunez MT, Garrick MD, Raisman-Vozari R, and Hirsch EC. Divalent metal transporter 1 (DMT1) contributes to neurodegeneration in animal models of Parkinson's disease. Proc Natl Acad Sci U S A 105: 18578-83, 2008.

28. Snyder AM and Connor JR. Iron, the substantia nigra and related neurological disorders. Biochim Biophys Acta 1790: 606-14, 2009.

29. Song W, Su H, Song S, Paudel HK, and Schipper HM. Overexpression of heme oxygenase-1 promotes oxidative mitochondrial damage in rat astroglia. J Cell Physiol 206: 655-63, 2006.

30. Sykiotis GP and Bohmann D. Stress-activated cap'n'collar transcription factors in aging and human disease. Sci Signal 3: re3, 2010 
31. Vargas MR and Johnson JA. The Nrf2-ARE cytoprotective pathway in astrocytes. Expert Rev Mol Med 11: e17, 2009.

32. von Otter M, Landgren S, Nilsson S, Celojevic D, Bergstrom P, Hakansson A, Nissbrandt H, Drozdzik M, Bialecka M, Kurzawski M, Blennow K, Nilsson M, Hammarsten O, and Zetterberg H. Association of Nrf2-encoding NFE2L2 haplotypes with Parkinson's disease. BMC Med Genet 11: 36, 2010.

33. West MJ. New stereological methods for counting neurons. Neurobiol Aging 14: 275-85, 1993.

34. Zhang Y, Talalay P, Cho CG, and Posner GH. A major inducer of anticarcinogenic protective enzymes from broccoli: isolation and elucidation of structure. Proc Natl Acad Sci U S A 89: 2399-403, 1992.

35. Zhao F, Wu T, Lau A, Jiang T, Huang Z, Wang XJ, Chen W, Wong PK, and Zhang DD. Nrf2 promotes neuronal cell differentiation. Free Radic Biol Med 47: 867-79, 2009.

Address correspondence to: Prof. Antonio Cuadrado

Departamento de Bioquímica Instituto de Investigaciones Biomédicas "Alberto Sols"

UAM-CSIC

C/Arturo Duperier 4 28029 Madrid

Spain

E-mail: antonio.cuadrado@uam.es

Date of first submission to ARS Central, October 22, 2010; date of final revised submission, January 10, 2011; date of acceptance, January 21, 2011.

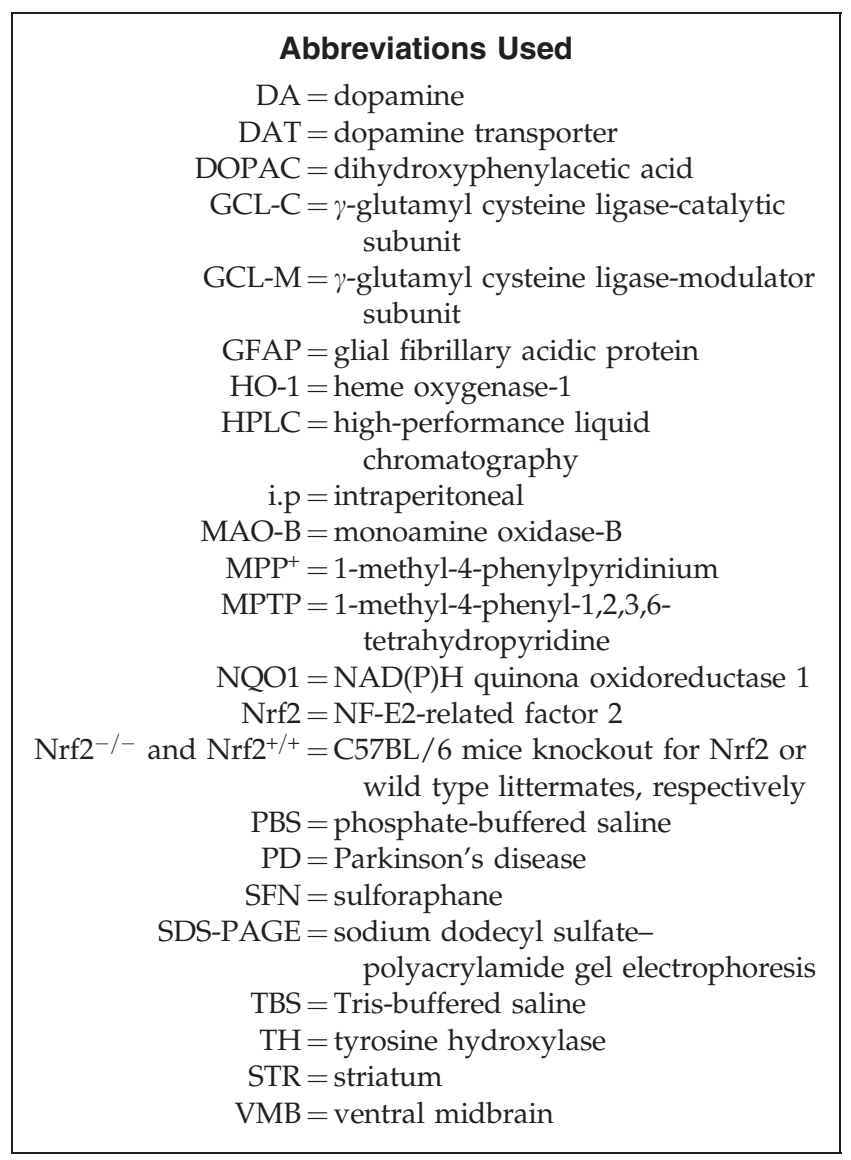

